\title{
Impact of Processing Factors on Quality of Frozen Vegetables and Fruits
}

\author{
R. G. M. van der Sman ${ }^{1}$
}

Received: 29 January 2020 / Accepted: 26 February 2020 / Published online: 27 May 2020

(C) The Author(s) 2020

\begin{abstract}
In this paper I review the production of frozen vegetables and fruits from a chain perspective. I argue that the final quality of the frozen product still can be improved via (a) optimization of the complete existing production chain towards quality, and/or (b) introduction of some promising novel processing technology. For this optimization, knowledge is required how all processing steps impact the final quality. Hence, first I review physicochemical and biochemical processes underlying the final quality, such as water holding capacity, ice crystal growth and mechanical damage. Subsequently, I review how each individual processing step impacts the final quality via these fundamental physicochemical and biochemical processes. In this review of processing steps, I also review the potential of novel processing technologies. The results of our literature review are summarized via a causal network, linking processing steps, fundamental physicochemical and biochemical processes, and their correlation with final product quality. I conclude that there is room for optimization of the current production chains via matching processing times with time scales of the fundamental physicochemical and biochemical processes. Regarding novel processing technology, it is concluded in general that they are difficult to implement in the context of existing production chains. I do see the potential for novel processing technology combined with process intensification, incorporating the blanching pretreatment—but which involves quite a change of the production chain.
\end{abstract}

Keywords Freezing $\cdot$ Cellular tissue $\cdot$ Food quality $\cdot$ Causal network

\section{Introduction}

Freezing is a widely used long-term preservation method for foods, where they retain attributes associated with freshness much better than other conventional preservation methods like canning and drying [1]. But especially the texture of cellular foods, like meat, vegetables and fruits, can be strongly impacted by the freezing process. Above all, vegetables often require blanching prior to freezing to prevent enzymatic browning. Blanching already impacts the vegetable texture. Fruits are seldom blanched, but due to their relative softness they are more severely impacted by freezing than vegetables. Via research projects with industry I have learned that significant improvements to the textural quality of fruits and vegetables can still be made. This is also indicated by the wealth of recent studies on the application

\section{R. G. M. van der Sman}

ruud.vandersman@wur.nl

1 Wageningen Food and Biobased Research, Wageningen University and Research, Wageningen, Netherlands of novel processing to improve the freezing process, like ultrasound and high-pressure freezing. There are several review papers on these novel technologies [2-6], but most of these papers focus on freezing as a single unit operation, without considering it as part of the complete frozen food production chain. An exception is the review paper, where novel technological developments in both blanching and freezing unit operations on vegetables are discussed [7].

Via this review I like to show that improvement of frozen vegetables and fruits can be obtained via (1) optimization of the total production chain of frozen foods and (2) introduction of some promising novel processing into the production chain, combined with process intensification. Literature shows there is very little study towards the optimization of the production chain. Only, a limited number of studies investigate the interaction between blanching and freezing steps [7, 8]. The usefulness of novel technology is often evaluated on the basis of the reduction of energy usage or food quality. As food losses and waste have much more impact on sustainability than energy usage [9], I will focus on the improvement of food quality, and in particular to the textural quality. 
Still, there is not sufficient knowledge on how freezing impacts on the matrix of tissue-based food materials like vegetables, fruits, and meat, via the freeze concentration and the mechanical stress imparted by the growing ice crystals [10]. For example, one of the major impacts of freezing on vegetables and fruits is the drip loss occurring after thawing. This drip loss occurs due to changes in water holding capacity of the food imparted by freezing. These changes and their physical causes are hardly discussed in the literature, with a few early exceptions discussing freezing of starch-rich foods [11], and meat [12-15].

Hence, before discussing effects of the different unit operations on the final quality of the frozen vegetables and fruits, I discuss the physics and (bio)chemistry of water holding and ice formation in plant tissue, using insights from the fields of cryopreservation of tissue [16-19], and freezing tolerance in plants [20-24]. As freezing and thawing imparts dehydration and subsequent rehydration of the tissue, one can expect many similarities with drying and rehydration of plant tissue [25-27].

Subsequently, I discuss the production chain of both vegetables and fruits, and the novel technologies, which can be applied in these chains. I have evaluated how each unit operation in the processing chain impacts physicochemical factors of relevance to the final quality of frozen fruits and vegetables. This evaluation is summarized in a so-called causal network linking processing factors via physicochemical factors to final product quality factors. Finally, I discuss modifications of the production chain for improved final product quality.

\section{Physics and Chemistry During Freezing of Plant Tissue}

Here, we discuss the physics and (bio)chemistry of water holding and ice formation in plant tissue. For the latter insights will also be obtained from the field of cryopreservation of tissue [16-19], and freezing tolerance in plants [20-24]. As freezing and thawing impart dehydration and subsequent rehydration of the tissue, one can expect many similarities with drying and rehydration of plant tissue [25-27].

\section{Steps in the Freezing Process}

\section{Supercooling and Nucleation}

Freezing can only happen if the food material is below freezing point, i.e., it has to be supercooled. The freezing does not happen immediately, because first ice crystals have to be nucleated. A cluster of liquid water molecules has to adapt to the ice crystal structure, and only a cluster of sufficient size can outgrow to an ice crystal. A cluster smaller than the so-called critical nucleus size will remelt again. The nucleation process is a balance between two opposing energy contributions: (a) the energy gain via the formation of the ice crystal structure and (b) the energy cost of forming an interface between the nucleated ice crystal and the unfrozen liquid phase. Only at the so-called critical nucleus size the energy gain is larger than the energy cost of forming the interface. It is said that the nucleation process has to overcome the energy barrier imposed by the surface energy. Via classical nucleation theory [28] one can calculate the critical nucleus size and the change of forming a nucleus, that is larger than the critical size and will outgrow. The change of nucleation depends largely on the amount of supercooling, the difference between freezing point and the actual temperature of the unfrozen phase. For pure water without any impurities, nucleation will happen only at $T=-40{ }^{\circ} \mathrm{C}$. If foreign material is present in the solution, having asperities or hydrophobic properties, ice can nucleate at much smaller degrees of supercooling due to the lowering of the energy cost of forming an interface.

It was commonly assumed that food is full of foreign material, that ice will form quite instantly, already at several degrees of supercooling, as stated in the Recommendation of the International Institute of Refrigeration [29]. However, scientific literature shows that significant supercooling occasionally can occur. Some vegetables like fresh garlic and shallots show a high capacity for supercooling [29, 30]. Few studies have reported a moderate supercooling of other vegetables like broccoli, cauliflower [30], strawberries [31], tomatoes [32], and potato slices [33]. Also in gel-like food products supercooling is observed like soy tofu [34], agar gels [35], tylose [36], agar/maltodextrin gels [37] and rice gels [38]. The amount of supercooling will determine the nucleation rate (the number of ice crystals formed per unit of time). Supercooling is well observed in recordings of product temperature at low heat transfer rates, such that the heat release during nucleation and further ice crystal growth cannot be cooled away fast enough, leading to temperature rise after nucleation [38].

The homogeneous nucleation temperature of pure water is $40 \mathrm{~K}$ lower than its freezing point. Surprisingly, in aerosols with solutes added the difference between freezing point and nucleation temperature remains $40 \mathrm{~K}$ [39]. The nucleation temperature is independent on the type of solute, but only on the water activity, similar to the freezing point (as follows from Clausius-Clapeyron [40, 41]). It is also assumed that the nucleation rate is a function of the water activity.

Heterogeneous nucleation can also occur in aerosols, if organic solutes are present in the crystalline state immersed in the aerosol for example [42]. Dicarboxylic acids are such solutes which are non-volatile, and have low solubility. Also biopolymers, especially proteins, are thought to promote heterogeneous nucleation in food [43-46]. Also, for 
heterogeneous nucleation it holds that the nucleation temperature depends only on water activity. Consequently, there is a fixed difference between equilibrium freezing point and nucleation temperature $[42,46]$. The heterogeneous nucleation temperature is always higher than the homogeneous nucleation temperature. Similar effects are observed during spray freezing of coffee [47].

The heterogeneous nucleation temperature does depend on the type of nucleation site (organic/inorganic crystal or biopolymer), and the (partial) wetting of the nucleation site. Importance of the interface on nucleation is shown in a recent study [48]. If air/water interface is sealed by oil, the nucleation of ice at the interface is highly suppressed. Even, the nucleation cannot be initiated via mechanical shocks or ultrasound. Also, nucleation can be suppressed by alcohols, which form an intricate structure at the interface due to their amphipathic nature.

In the fields of cryopreservation of tissues [19] and freeze-drying of pharmaceuticals [49] the phenomenon of supercooling is much more acknowledged and observed. In these fields good control of ice morphology is demanded. Hence, there are serious research activities towards methods of controlling the ice nucleation event, which are based either on formulation or on process conditions. For the control of nucleation via formulation one can obtain much inspiration from organisms showing high cold tolerance [50]. Furthermore, food science can learn from this field how supercooling and ice nucleation depend on cell volume [51]. Nucleation is expected to occur earlier for tissues with smaller cells, due to the higher amount of cell surface (wall) area. Furthermore, at slow to moderate freezing rate ice nucleation is expected to happen in the extracellular space [52] (Fig. 1).

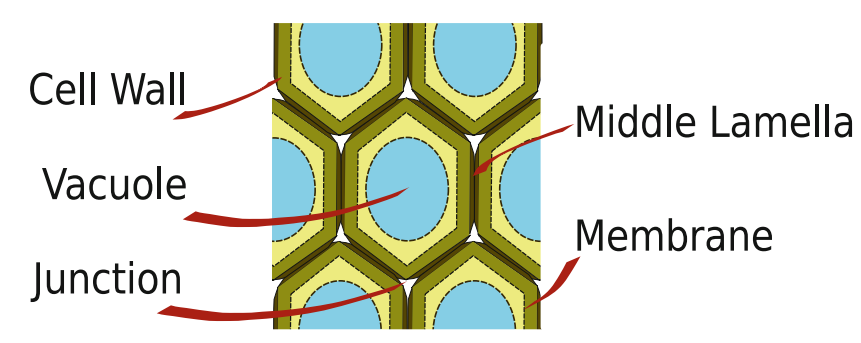

Fig. 1 Cellular structure of vegetables and fruits

\section{Crystal Growth}

As the supercooled state, where ice crystals are nucleated, is not at equilibrium, ice crystals will grow to restore equilibrium. Solutes or biopolymers present in the unfrozen phase are excluded from the growing ice crystals. Hence, the growing ice crystals push the solute and polymers forward in front of the growing ice crystals, leading to gradients of solutes or density in the biopolymeric matrix. For growth of the ice crystals the liquid water has to diffuse through these concentrated boundary layers of solute or biopolymer [53, 54].

As stated above, the formation of ice releases energy (latent heat), and consequently the (local) temperature will increase and approach the equilibrium freezing point. This release of latent heat after nucleation is called recalescence [55]. If the freezing rate is sufficiently slow, the average temperature and solute/biopolymer concentration will follow closely the freezing line until the temperature of the cooling medium is reached. Food is commonly frozen at temperatures around $-18{ }^{\circ} \mathrm{C}$, which is the common storage temperature for frozen food. The changes in the state of the unfrozen phase during the freezing operation is illustrated in Fig. 2. Here we have used the phase diagram of sucrose, which is a good model system for fruits rich in sugar. Observe that initially the temperature drops below the freezing line, where the unfrozen liquid enters the supercooled state. At a sufficient degree of supercooling ice crystals are nucleated (event 1 ), and the temperature will rise due to recalescence. Simultaneously, the mass fraction of water in the unfrozen phase decreases due to the freeze concentration effect. After a brief moment, the state of the food will commonly follow

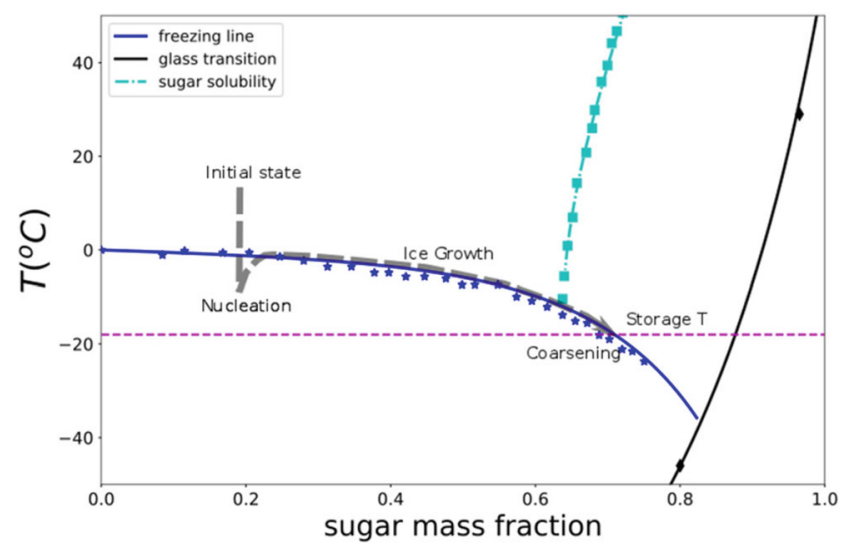

Fig. 2 Different steps in freezing process as depicted in the supplemented state diagram of sucrose, showing the freezing line, sucrose solubility, and glass transition line. Sucrose is viewed as model system for fruit. Path taken by state of the system during freezing is shown by the dashed gray line 
the equilibrium freezing line, until the outside temperature of cooling medium is reached (here $-18{ }^{\circ} \mathrm{C}$ ).

Depending on the process conditions and the food material properties, the ice crystal growth rate is either determined by the heat transfer or by the diffusion rate. The resulting ice crystal size is often the resultant of the interaction between ice crystal growth and the diffusion of the excludes solutes and/or biopolymers, as we have discussed earlier [53, 54]. At slow freezing rates the ice crystal size is independent of the number of initial nuclei, but depends only on the freezing rate, and initial solute concentration [54]. Only at quite fast freezing rates, where the state of the food remains significantly below the equilibrium freezing line, ice crystal size can depend on the number of initial nuclei.

\section{Coarsening}

The freezing operation is commonly stopped if a minimal product temperature is reached. The frozen food is transferred to storage facilities, where temperatures around $-18{ }^{\circ} \mathrm{C}$ are maintained. As one can observe in Fig. 2, this storage temperature is likely to be above the glass transition temperature of the food matrix. This means that moisture still has sufficient mobility to diffuse through the unfrozen phase, and allow changes in the morphology of the frozen phase. Consequently, the physical process of ice coarsening (or Ostwald ripening [56-58]) can still proceed. The coarsening leads to further growth of the largest ice crystals, at the expense of smaller ice crystals.

Temperature fluctuations around the storage temperature lead to ice crystal melting and regrowth [59,60], which is assumed to be a different mechanism than coarsening via Ostwald ripening. Hydrocolloids are assumed to have a large impact on this melting/regrowth mechanism, as shown for ice creams [59]. One can assume that cell wall material in frozen fruits and vegetables act in a similar way [61]. Hydrocolloids are thought to have a stabilizing effect on the ice crystal distribution, thus limiting the coarsening via temperature fluctuations. The hypothesis behind the stabilizing effect of hydrocolloids is that they hinder the diffusion of solute towards/away from the interface of a melting/growing ice crystal [59]. However, in carrots it is found that ice crystals grow due to temperature fluctuations during storage [60].

\section{Interaction of Ice Formation with Plant Tissue}

In the discussion of the interaction of ice formation with plant tissue, we follow the classification in damage as used by Reid [62]. He distinguishes (1) dehydration of the cell due to the location of ice nucleation, (2) solute damage induced by freeze concentration of the intracellular fluid, and (3) mechanical damage via the stress imparted by the expanding ice phase. To understand the damage induced by dehydration and loss of turgor, it is important to have an understanding of water holding capacity of foods. This is first discussed below.

\section{Water Holding Capacity of Vegetables and Fruits}

The water holding capacity of cellular tissue of plants like vegetables and fruits strongly depends on their structure, which is depicted in Fig. 1. Plant cells comprise of vacuole embedded in cytoplasm. Both vacuoles and cytoplasm are surrounded by lipid membranes, which are impermeable to most of the solutes, but they are permeable to water. The vacuole contains simple solutes like sugars, while the cytoplasm contains mainly biopolymers like proteins. In some vegetables like potatoes the cytoplasm is also rich in starch. The cell membrane is enveloped by the cell wall, which gives the plant tissue strength. The individual cells adhere to each other via the middle lamella, which is rich in pectin. There is little adherence in the three-way junctions, which often contains air and provides pathways for gas diffusion [26, 27, 63, 64].

Due to the solute impermeability of the vacuole membrane an osmotic pressure is generated, which attracts fluid from the extracellular space, the apoplast. The cell walls are viewed part of the apoplast, and connect to the vascular tissue-allowing for transport of water, nutrients and assimilates. The inflation of the vacuole leads to expansion of the cell, and stretching of the cell wall, which can be regarded as a biopolymer network. This deformation of the cell wall leads to mechanical stress, which will counteract the osmotic pressure. If the mechanical stress balances the osmotic pressure, the cell is at full turgor [26, 27, 63-65].

In a recent paper we have elucidated the physical theory behind the water holding of vegetables [65], which extends our earlier papers on Flory-Rehner theory [66]. In fresh vegetables water is held in three compartments: (a) in the intracellular space, both the vacuole and the cytoplasm, (b) the extracellular cell wall material, and (c) the capillary space, which can be filled with fluid after vacuum impregnation [67]. The water holding in the intracellular space critically depends on the integrity of the cell membranes, otherwise leading to the loss of osmotic pressure and turgor. The cell wall material (CWM) can be regarded as a hydrogel, containing hemicellulose and pectin, embedded with cellulose fibers [65]. The water holding of the CWM can theoretically be described by Flory-Rehner theory and its extensions. The theory describes the amount of water holding of the gel as function of its hydrophilicity (as indicated by the FloryHuggins interaction parameter) and the cross-link density. 
During food processing the cross-link density of CWM is often modulated, especially during blanching [64]. During conventional blanching the thermal solubilization of pectin via beta-degradation lowers the cross-link density, whereas during long-time-low-temperature blanching the cross-link density is increased via the activation of the PME enzyme, which de-esterifies pectin, and the subsequently crosslinking via calcium ions. As pectin is a polyelectrolyte, extensions of Flory-Rehner theory learns that its water holding is also influenced by ionic strength and $\mathrm{pH}$ of the fluid the CWM is immersed in $[68,69]$.

If the integrity of the cell membrane is lost, also the osmotic pressure and turgor pressure are lost. The stretched network of the CWM will relax back to its zero stress state, thereby absorbing a little water [65]. Due to the relaxing of the CWM the intracellular space will shrink in volume, which cannot be compensated by the increase of water holding of the relaxed CWM. The excess fluid will be located in the extracellular capillary space, which is enlarged compared with the full turgor state. Now the water in the intracellular space and the extracellular capillary space is only held by capillary forces, and consequently it can easily be pressed out by external forces, as occur during eating $[65,70]$ or it can drain easily via gravity, for example appearing as drip loss after thawing or slicing.

\section{Location of Nucleation}

One of the important factors for the interaction of ice and the plant tissue is the location of nucleation with respect to the cell, which imparts the integrity of the cell membrane. In cryopreservation it is crucial that tissue survives the freezing operation, for which it is critical to control or even prevent intracellular ice formation [71]. If the size of the intracellular ice approaches that of the cell size, it will puncture the cell membrane of the vacuole. Consequently, the membrane looses its integrity, and solutes diffuse to the extracellular space. The osmotic pressure and turgor pressure are lost. The stretched cell wall material will return to its relaxed state, and will squeeze out liquid from the intracelluar space. For foods like fruits it is important to maintain cell membrane integrity and turgor.

In plant tissue it is energetically favorable that ice nucleation happens in the extracellular space. The extracellular space is thought to have quite a number of heterogeneous nucleation sites [72], while intracellular ice formation often requires homogeneous nucleation [73]. The air/liquid interface in the junctions between cells (if filled with air) can be a preferred nucleation site [74]. Extracellular nucleation will indeed happen at sufficiently slow freezing rates. Extracellular ice growth extracts water from the cell. There will be only extracellular ice growth if the water extraction rate from the cell can keep up with the ice formation rate
[72]. Otherwise, the cell gets sufficiently supercooled to ice nucleation to happen. Thus, at relatively fast freezing rates both extracellular- and intracellular ice formation will happen. If the tissue is suddenly immersed in liquid nitrogen, the nucleation is mostly intracellular, because the temperature gets quickly below the homogeneous nucleation temperature (around $-40{ }^{\circ} \mathrm{C}[73]$ ). However, sufficiently rigid cell wall can prevent intracellular ice nucleation, due to the development of negative pressures, which is a consequence of the deformation of the stiff cell wall [73].

If nucleation happens extracellular the cell membrane need not to loose its integrity. Growth of extracellular ice will draw water also from the intracellular space, which will freeze concentrate and shrink (and gets in the state known as cytorrhysis [72]). As the volume of the cell membrane cannot shrink, as it contains lipids only, the shrinkage of the cell can lead to buckling and damage of the cell membrane. Some of the invaginations of the cell membrane can bud off as endocytic vescicles, leading to reduction of the cell membrane area. Hence, upon thawing the melt water of extracellular ice returns to the cell (via osmosis), which will expand again. Due to the reduced area of the membrane due to endocytosis, it will burst just before it is fully hydrated [72].

\section{Freeze Concentration}

The intracellular space and vacuoles also contain sugars, salts and possibly some acids [75]. Hence, freeze concentration will lead to increase of the ionic strength, and change in $\mathrm{pH}$ via the decrease of water activity. These altered conditions may lead to protein denaturation or permeabilization of the cell membrane. Freeze concentration also has influence on the biochemistry, as it increase the substrate concentration for enzymes [76]. During freezing of vegetables enzyme activity can lead to undesired browning due to loss of the integrity of the vacuole, via which substrates get into contact with membrane-bound enzymes like PPO, leading to discoloring [77, 78].

Consequently, many vegetables are blanched before freezing. Yet, blanching also imparts the textural quality of the vegetables due to (1) loss of membrane integrity via the enhanced temperature, (2) the solubilization of pectin, and (3) enhanced cross-linking of cell wall material with calcium made possible via the modification of pectin by the PME enzyme [79-82]. Hence, for the final textural quality of frozen vegetables the conditions for blanching and freezing should be well balanced.

Freeze concentration can also enhance oxidation processes [83], especially to the lipid cell membranes [72]. Furthermore, retrogradation of starch can happen in cooked products like par-fried potato products $[84,85]$. During retrogradation recrystallization of amylose is enhanced. For 
products like frozen rice gels it is shown that retrogradation leads to syneresis, which is released from the food after thawing as drip loss [86].

Note that the low product temperature slows down the diffusion and reaction kinetics, and thus counteracts the effect of freeze concentration. At temperatures of the frozen storage the slowed-down diffusion and reaction kinetics commonly overwhelms the effect of freeze concentration $[87,88]$. But at temperatures just below freezing point, effects of freeze concentration can be considerable. Mind that, these conditions reoccur during thawing. Consequently, also the rate of thawing should be taken into account during the design of the frozen food production chain.

\section{Mechanical Stresses}

As the density of ice is smaller than liquid water, the food will expand and its matrix will be subject to tensile stresses upon ice formation $[89,90]$. Later if coolant temperatures are reached the stresses will be compressive as the density of ice increases with the lowering of temperature [91]. The simultaneous occurrence of compressive and tensile stresses make the food especially vulnerable to freeze cracking. Freeze cracking occurs particularly at quite high freezing rates as occur during cryogenic freezing. During freeze cracking cells will be ruptured straight through the cells.

During slower freezing rate the growth of adjacent ice crystals can lead to localization of stresses [92-94], which will rupture the food matrix at weak points. If the vegetable has been blanched the weak spots are in between cell walls, where pectin has been solubilized. This will lead to separation of cells. Also, in frozen living plants mechanical stresses are thought to be a major cause in freezing damage [72].

The growth of adjacent ice crystals towards each other compresses the cell wall material in between. We hold the hypotheses that due to the compression extra crosslinks or hydrogen bonds will be made in the cell wall material, which will reduce its water holding capacity, but it will also hinder the swelling back to its original density. Reduction of the cell wall thickness after freezing has been observed in living plants [72]. This is also apparent in the structure of rehydrated vegetables which have been subject to slow freezing and subsequent (freeze) drying [70]. The compression of a starch matrix as in freezing (par-fried) potato products will probably enhance the retrogradation, which also lowers the water holding of the starch matrix [84, 85].

It is also claimed that freezing and frozen storage leads to breakdown of pectin (depolymerization). For papaya it is shown that multiple freeze/thaw cycles increases to amount of soluble pectin, which indicates indeed the breakdown of pectin. This results in further weakening of the cell wall matrix, and lowers its water holding capacity [95]. For (nonblanched) apples also decreased cell adhesion after thawing is observed [96]. This has been explained due to the action of enzymes on the cell wall material, which have come into contact due to rupture of the cell membranes.

\section{Impact of Processing Steps in Production Chain}

A typical production chain of frozen vegetables or fruits is shown in Fig. 3, which is line with production chains described in several patents [97-99] and textbooks [100]. The production chain is also consistent with the typical production chain for frozen fries as given by Scanlon [101], but I have not included par-frying explicitly, but it can be viewed as just another means for dehydration. The main difference between vegetable and fruit processing is that vegetables are commonly blanched, while it is absent for fruits. For the soft fruits it is important to retain the full turgor state, which will otherwise lead to detrimental loss of texture. Below, I discuss how each step in this production chain impacts the final quality, and the potential improvement of that, as offered by novel technology. Promising novel technologies are summarized in Tables 1 and 2.

\section{Cold Storage}

After harvest fruits and vegetables are stored at low, non-freezing temperatures for buffering before further processing like freezing. Optimal long-term chilled storage conditions are found in literature [102]. In general fruits and vegetables are stored at low temperatures, provided that chilling injury or freezing injury is prevented [103]. Due to the applied temperatures and storage time, this cold storage will have little impact on the freezing quality. However, there is some potential in inducing cold acclimation, which is the physiological adaptation of plants to freezing conditions [10, 104-106], This will be discussed below.

Many overwintering plants will show cold acclimation, if ambient temperature declines slowly below $5{ }^{\circ} \mathrm{C}[23$, 107]. The physiological adaptations are targeted at the survival of the dehydrated cell after extracellular ice formation. The primary freezing injury to living tissue is the permeabilization of the cell membrane. The physiological adaptation comprises of (1) changes in lipid composition of membranes, making them less vulnerable to chilling injury, (2) increased accumulation of solutes in the vacuole, (3) synthesis of special proteins for protection of cell membrane, and modulation of the ice growth similar to antifreeze proteins, and (4) synthesis of anti-oxidants. Antioxidants are required because the freeze concentration of the 


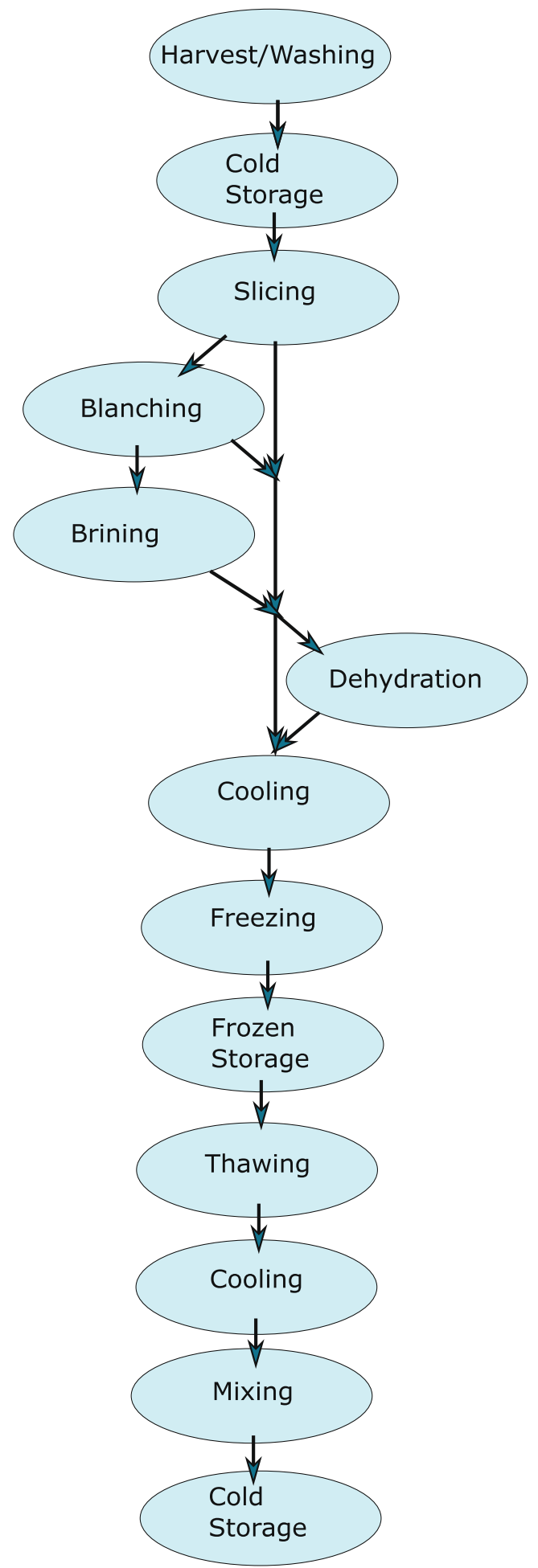

Fig. 3 Process flow sheet for frozen vegetables and fruits. Prior to freezing the produce may either be blanched, brined and/or dehydrated (as in dehydrofreezing)

cell can promote oxidation reactions. Even, other proteins can be synthesized, that promote ice nucleation in the extracellular space [74].
The cold acclimation is thus primarily targeted at protection of the cell membrane, or prevention of the dehydration of the cell, via an increase of its osmotic pressure. In acclimated tissues, both the cell membrane and cell wall have become effective barriers for extracellular ice [20, 22]. Non-acclimated tissues often show intracellular ice growth, originating from extracellular ice via secondary nucleation. Membranes with chilling injury allow passage of ice from the extracellular space to the intracellular space. Intracellular ice formation is often lethal for living tissue.

Cold acclimation as a pretreatment to freezing has been investigated for carrots [10] and spinach [106], showing a significant decrease of freezing damage. Carrots have been stored at $0{ }^{\circ} \mathrm{C}$ to elicit cold acclimation. Cold acclimation of spinach leaves is elicited via changing the environmental temperature during growth. The experienced cold stressinduced cold acclimation.

However, if the acclimated vegetable is subject to blanching several protective effects provided by proteins or membrane composition will be eliminated, due to protein denaturation and thermal injury to the membrane [10]. Still, the amount of accumulated solutes in the vacuole will lead to a lowering of freezing point and decrease in amount and size of ice crystals.

Cold acclimation will be difficult for (sub)tropical produce. For these produces the cold storage temperature must also remain above a critical value, otherwise, chilling injury happens, leading to damage of the cell membrane, and loss of turgor [22].

\section{Slicing}

Processed vegetables and fruits are often sliced or cut to reduce size for consumer convenience, or to enhance the heating rate of thermal processing like blanching, cooling or freezing. Slicing is often done if the product is still in the turgid state, because of its firmness. Hence, the plant is still metabolically active, and slicing will trigger biochemical defense mechanisms. Via slicing phenolic substrates, present in the vacuole, come into contact with enzymes leading to browning. Also the ripening biochemistry is accelerated, leading to faster softening of texture [108-110]. Also, slicing can enhance the loss of leaching of solute if further processing is performed in water (like blanching).

The negative effects of the activated biochemistry due to slicing can be stopped if the food is immediately blanched. For fruits blanching is often not done, and they can be frozen directly after slicing. As the freezing takes time, the sliced fruits can be dipped in water, to infuse it with anti-oxidants, $\mathrm{Ca}^{2+}$ and PME enzyme [111]. Anti-oxidants can retard the browning, and the $\mathrm{Ca}^{2+}$ and PME enzymes enhance the texture via cross-linking pectin. Furthermore, $\mathrm{Ca}^{2+}$ also retards the accelerated softening. 
Table 1 Critical factors related to drip loss

\begin{tabular}{|c|c|c|c|}
\hline Process step & Input & Effect & Correlation with drip \\
\hline \multirow[t]{3}{*}{ Cold acclimation } & \multirow[t]{3}{*}{ Temperature/time } & Amount solute & - \\
\hline & & AFP synthesis & - \\
\hline & & Anti-oxidants & 0 \\
\hline \multirow[t]{2}{*}{ Slicing } & \multirow[t]{2}{*}{ Size } & Tissue rupture & + \\
\hline & & Blanching/freezing rate & - \\
\hline \multirow[t]{2}{*}{ PEF impregnation } & \multirow[t]{2}{*}{ Solute concentration } & Amount of solute & - \\
\hline & & Antifreeze protein & - \\
\hline \multirow[t]{5}{*}{ Blanching } & Temperature/time & Enzyme inactivation & 0 \\
\hline & Size & Loss of turgor & + \\
\hline & Heat transfer coefficient & Pectin solubilization & - \\
\hline & \multirow[t]{2}{*}{ Wet/dry medium } & Solute leaching & + \\
\hline & & Loss of turgor & + \\
\hline Blanching & LTLT & $\mathrm{PME} / \mathrm{Ca}^{2+}$ cross-linking & $+/-$ \\
\hline Dehydration & Temperature/time & Amount of solute & - \\
\hline \multirow[t]{2}{*}{ Freezing rate } & Heat transfer coefficient & Ice crystal size & - \\
\hline & Temperature & Amount of ice & - \\
\hline \multirow[t]{3}{*}{ Frozen storage } & \multirow[t]{2}{*}{ Temperature/time } & Stress relaxation & - \\
\hline & & Pectin solubilization & - \\
\hline & Temp. fluctuations & Ice crystal size & + \\
\hline \multirow[t]{2}{*}{ Thawing } & \multirow[t]{2}{*}{ Temperature/time } & Stress relaxation & - \\
\hline & & Enzyme reactivation & 0 \\
\hline
\end{tabular}

Slicing plant-based products in the turgid state requires quite some energy, and consequently one sees the application of PEF (pulsed electric field) technology to puncture the cell membranes, leading to a reduction or loss of turgor pressure, and thus a reduction of the energy required for slicing [112, 113]. It is applied in practice to frozen potato products. Also, it is claimed that PEF before slicing can already provide (partial) inactivation of enzymes [114]. However, this claim is controversial as it is debated that the enzyme inactivation can just be imparted by the thermal effects of PEF [115].

\section{Blanching}

For consideration of the blanching of vegetables on freezing, it is important to know the actual functionality of this pretreatment. Often, it is primarily intended to inactivate enzymes. For green vegetables it is important to inactivate lipid oxidase [116, 117]; otherwise, offodours can develop due to lipid oxidation during freeze concentration. Also one desires to inactivate peroxidase, to reduce enzymatic browning [118, 119]. However, for some vegetables like carrots it is questionable if blanching is required to inactive enzymes, for they have limited impact on texture and browning [8]. Other studies state that a very quick treatment of dipping carrots in boiling water for 10$20 \mathrm{~s}$ is sufficient for inactivation enzymes responsible for lipid oxidation [10].

The temperature treatment during blanching will give undesired effects on the texture. First of all, the permeability of cell membranes is imparted, leading to loss of turgidity [120]. Especially for fruits, this is highly undesired, and consequently fruits are seldom blanched prior to freezing [121]. Furthermore, blanching at high temperatures, $T>80{ }^{\circ} \mathrm{C}$, will solubilize the pectin of the cell walls via the $\beta$-elimination process, leading to cell separation and weakening of the tissue [7]. Water holding properties of cell wall materials are imparted by the solubilization of pectin [64].

Common blanching processes involve the immersion of the vegetables in hot water or steam [7]. Blanching via immersion in hot water renders a good heat transfer, but it can also lead to leaching of solutes. Sliced products are of course extra vulnerable to leaching of solutes. The loss 


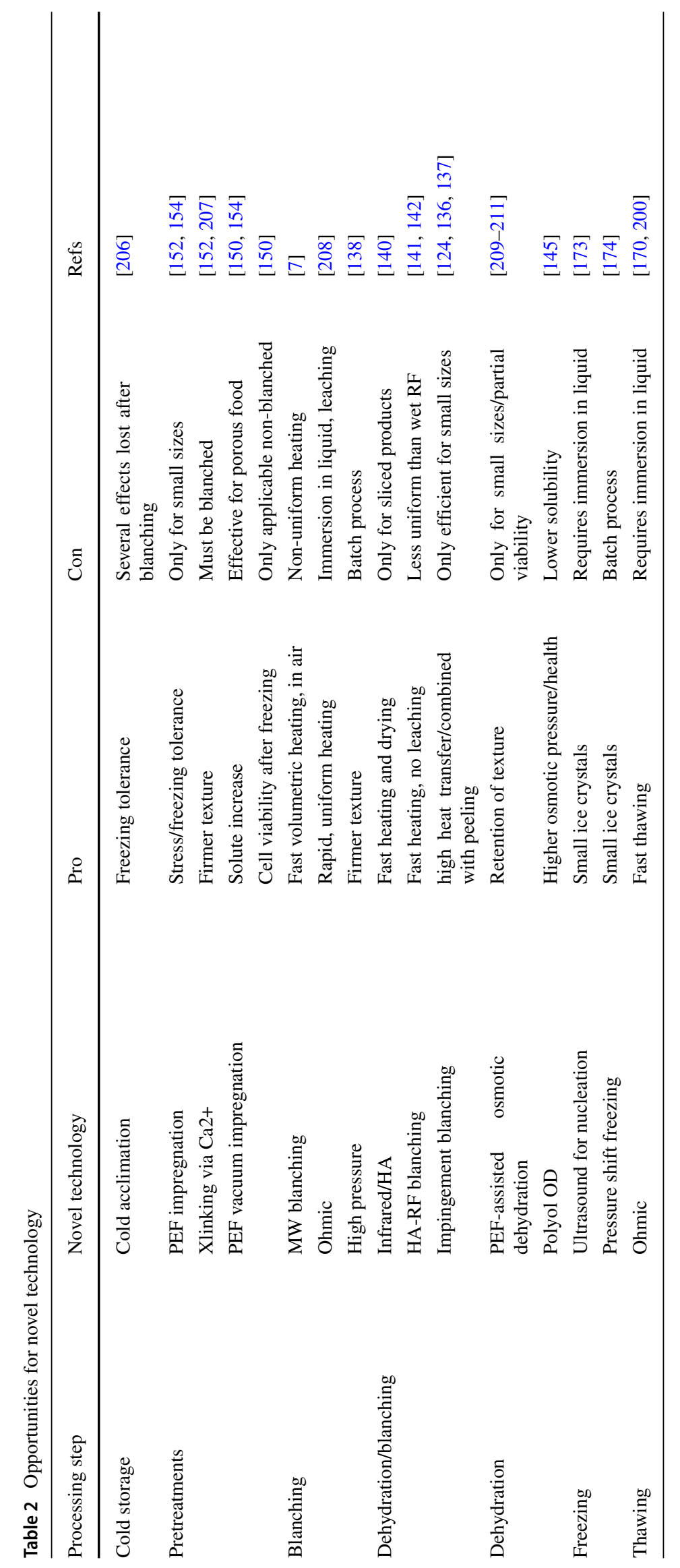


of solutes implies an increase of the freezing point, and therefore an increase of amount and size of ice crystalswhich are both negative for freezing quality. Solute leaching is reduced via steam blanching [122]. Steam blanching is also a fast process, due to the efficient transfer of heat via the condensation of steam [123]. The use of superheated steam allows for temperatures below $100{ }^{\circ} \mathrm{C}[124,125]$.

The impact of the thermal treatment during blanching on texture can be reduced via two strategies: (a) LTLT (low temperature long time) blanching or (b) HTST (high temperature short time) blanching [126-128]. During LTLT blanching the low temperature enhances the activity of the PME enzyme, which enhances the strength of the cell wall via mediating cross-links between pectins with $\mathrm{Ca}^{2+}$ [129]. Many vegetables already contain sufficient calcium in their cell wall material [126, 130], but it can be added to the blanching water, or infused via vacuum impregnation $[131,132]$. The strengthened cell wall will have reduced water holding capacity but may resist better the compression induced by the growing ice crystals during freezing [8].

The HTST blanching strategy can be applied with technologies having a high heating rate. The texture degradation is reduced if the heating rate is significantly faster than the kinetics of the $\beta$-elimination of pectins [133]. A faster heating rate is often the target of novel blanching technologies like Ohmic heating [7], or radio-frequency or microwave heating $[134,135]$. These are volumetric heating methods, which can heat foods up to $80{ }^{\circ} \mathrm{C}$ within one minute. The volumetric heating makes the heating rate quite independent of the size of the product. However, especially via microwave heating, there is often a large non-uniformity in temperature-making such a blanching technology hard to design and control. The HTST strategy can also be achieved by enhanced heat transfer coefficients as in jet impingement technology [124, 136, 137]. However, the enhanced heat transfer coefficient is only efficient if the size of the product is small enough that the heating rate is still determined by the external heat transfer coefficient, rather than the thermal conduction inside the product.

Good enzyme inactivation, while maintaining a firm texture, can be achieved with high-pressure blanching [138, 139]. However, high-pressure treatment is a batch operation, requiring specialized equipment, which is difficult to incorporate in the continuous production chain of frozen vegetables and fruits.

Another measure against solute leaching is the addition of solutes to the blanching water [8, 132]. This can even promote the diffusion of solutes into the vegetable if the solute concentration in the blanching water is higher than in the tissue. The addition of solutes will lower the food's initial freezing point [8]. But, their effect might not be very large, due to diffusion barriers imposed by the cell wall material.
Some dry blanching techniques allow for combining the process with dehydration, i.e., drying, with the purpose of increasing solute concentration, and thus lowering of the initial freezing point, and the ultimate improvement of the quality of frozen product. Examples of these dry blanching technologies are infrared/hot air blanching [140], and blanching via hot air and radio-frequency heating [141, 142]. Dehydration can only be performed at practical time scales for small (sliced) products. Also, one must be careful and prevent case hardening, the formation of a dense skin on the product, which leads to a significant lower appreciation of the texture by consumers, and limits possible rehydration after thawing.

\section{Dehydration}

Potato products and some vegetables are air-dried after blanching to remove surface water to avoid clumping during freezing operation in the tunnel [97] or oil splashing during par-frying [101]. Dehydration can also be performed to improve the quality of frozen fruits and vegetables. The dehydration lowers the amount of water and increases thus the solute concentrations, and consequently it lowers the initial freezing point of the food-leading to smaller ice crystals and a smaller amount of ice formed. These combined processes of dehydration and freezing is known as dehydrofreezing [7, 52].

Although dehydrofreezing is already known for years, it has received little attention in the scientific literature. It has been argued that there is much room for improvement if the two processing steps are jointly optimized [52]. The dehydration step can be performed via conventional air drying [143] or via osmotic dehydration, but this process requires intact cell membranes [144]. This technology is then particularly applied to fruits, and to vegetables, which are nearly always blanched (destroying the integrity of the cell membrane). For vegetables, dehydration can conveniently be combined with blanching, as reviewed in the previous section.

To improve the quality of frozen vegetables or fruits the amount of water to be removed via dehydration should be in the order of 30-50\% [52]. Next to improvement of texture, there is also a reduction of freezing time, which significantly reduces energy consumption [52].

Osmotic dehydration is performed via immersing food in an osmotic solution, containing a high concentration of solutes like sugars or salts. The process has some negative side effects like leaching of solutes from the food, and the increase of salt or sugar levels of the food [144], which can impair the sensorial and nutritional value of the food. The nutritional constraints of sugar or salt in osmotic solutions can be lifted via the use of sugar replacers with smaller molecular weight such as polyols [145]. Per mass of solute 
they also offer higher osmotic pressure, i.e., a higher driving force for osmotic dehydration.

Furthermore, osmotic dehydration is a slow process [146] as (1) water has to pass through the cell membrane, which is the dominant resistance to mass transfer and (2) the dehydrated crust of the food with increased concentration of the solute from the osmotic solution has a decreased permeability. The temperature and solute concentration of the dehydration solution are limited because at high temperature or high osmotic pressure cell lysis will occur (also known as osmotic plasmolysis) [147, 148], leading to the loss of function of the membrane-becoming fully permeable. Generally, osmotic dehydration is performed at $30{ }^{\circ} \mathrm{C}$, avoiding the loss of cell membrane integrity [52]. Furthermore, the recycling of the osmotic solution is a concern from a technological and hygienic point of view [144, 146].

Significant enhancement of osmotic dehydration is via the combination with vacuum impregnation $[149,150]$. During this pretreatment the air in the intercellular space is removed and replaced by the osmotic solution. This pretreatment is especially advantageous for highly porous foods like apples. Recently, it is also applied to carrot and strawberries, where sugar impregnation is combined with $\mathrm{CaCl}_{2}$ and/or PME to promote cross-linking of pectin, which will increase the mechanical strength of the cell wall [151, 152].

Because osmotic dehydration is inherently a slow process, there has been a variety of research studies of improving the mass transfer rate via combining the dehydration with techniques like high pressure or pulsed electric fields (PEF) [146], with the purpose to increase (temporarily) the permeability of the cell membrane. The treatment should be mild enough, such that the resistance to mass transfer is lowered, but the loss of membrane permeability is reversible, such that full turgor can be restored after osmotic dehydration [5, 152].

Some studies concerning PEF-assisted osmotic dehydration have investigated whether the viability of the cells can still be retained after freezing. PEF is combined with vacuum impregnation of antifreeze agents and/or antifreeze proteins that are impregnated into the tissue, leading to enhanced cryoprotection of the tissue [153]. Retention of cell viability requires fast freezing rates as in cryogenic freezing, such that intracellular ice formation occurs. The small, round ice crystals will not puncture the cell membrane. However, this is achieved for few porous products, such as leafy vegetables (like spinach leaves) [154, 155], and fruits as strawberries [150] and apples [156]. However, the texture and drip loss is still comparable with a vacuum impregnation treatment without PEF [150].

If one tries to achieve retained cell viability via air dehydration, the drying must be done at very mild conditions to prevent permeabilization of the cell membrane, which happens at temperatures above 40 degrees [143]. It is suggested to use vacuum-microwave drying performed at low temperatures [52].

\section{Freezing Operation}

Commonly, industrially processed fruits and vegetables are frozen using air blast freezing in conveyor belt tunnels [100]. Air is forced by big fans over a mechanical refrigerator unit, and then over the belt with produce. The belt allows vertical airflow to pass through it. The air temperature is often set between -18 and $-40{ }^{\circ} \mathrm{C}$, and air velocities are in the order of $1 \mathrm{~m} / \mathrm{s}$. Heat transfer coefficients of $10-80 \mathrm{~W} / \mathrm{m}^{2} \mathrm{~K}$ are commonly reached [157, 158], which are not as high as in fluidized bed freezing or impingement freezing [159]. Hence, there is definitely room for improvement of final product quality and texture. One can follow two strategies to improve freezing, aiming at either (1) the enhancement of the freezing rate or (2) the enhancement ice crystal nucleation [5].

Earlier I have discussed how the freezing rate impacts the ice crystal size, and thus the food texture [53]. The freezing rate is determined by several factors, namely the size of the food, the heat transfer coefficient of the coolant medium, and the freezer temperature, as indicated by Planck's equation [53]. Heat transfer rate can be improved via enhancement of airflow velocity, as in jet impingement freezing $[160,161]$ or in fluidized bed freezing [162], or by choosing another coolant medium like a liquid in immersion freezing, or a cryogenic liquid or gas from liquid nitrogen or $\mathrm{CO}_{2}$ freezing [163]. Via jets of airflow impinging the surface of foods one can achieve a local heat transfer coefficient of $400 \mathrm{~W} / \mathrm{m}^{2} \mathrm{~K}$ [164]. It must be noted that the increase of air velocity also promotes mass transfer, i.e., the evaporation of water from the food, which might not be desired.

Cryogenic freezing is used in practice for freezing quite vulnerable fruits and vegetables, such as berries [151, 165, 166]. The high freezing rate of cryogenic freezing is mostly due to the low temperature of the coolant, cold nitrogen or $\mathrm{CO}_{2}$ gas or sprays-which is generated from solid $\mathrm{CO}_{2}$ or liquid nitrogen. The freezing temperature is due to the low boiling point of the cryogenic liquids, which are $-78{ }^{\circ} \mathrm{C}$ or $-196{ }^{\circ} \mathrm{C}$ for $\mathrm{CO}_{2}$ and $\mathrm{N}_{2}$, respectively. Both gases are quite inert and do not penetrate the food. Cryogenic liquids can also be sprayed on the foods, and the freezing is then enhanced by the required heat for the evaporation of the cryogenic liquid droplet on the foods surface [100].

In immersion freezing the cooling medium should remain liquid below $0{ }^{\circ} \mathrm{C}$, which can be mixtures of water/glycerol, water/ethanol or similar liquids as used in osmotic dehydration (sugar or salt solutions) [167, 168]. The heat transfer coefficients in liquids are considerably 
higher than those in airflow, which are in the range 150$1500 \mathrm{~W} / \mathrm{m}^{2} \mathrm{~K}$ [169]. During immersion freezing in such liquids there will be impregnation of food with solutes from the liquid if the food does not have any proper barrier. For large-sized foods like fish or meat, it is economical to use vacuum-sealed packagings as a barrier. However, if a similar liquid has already been used for osmotic dehydration, the use of immersion freezing in the same liquid can be a serious option for freezing fruits or vegetables, via combining freezing and osmotic dehydration [167]. Freezing rates can also be improved via the use of impingement technology.

There will be a limit to the freezing rate, as high freezing rates will impact the development of mechanical stress in the food, due to the volume expansion of ice [170]. At high freezing rates, the stress has insufficient time to relax. High stresses can lead to freeze cracking or damage during fast thawing [171].

At sufficient low freezing temperatures, the food attains the glassy state. The food is not in equilibrium but is supercooled. The amount of ice formed depends on the freezing rate [171]. However, if one thaws these supercooled foods too slowly, ice growth can occur at temperatures just below freezing point. All the protection offered by the glassy/supercooled state against freezing damage can be eliminated by the slow thawing [172].

For the stimulation of ice nucleation one has been tried several novel technologies, like ultrasound [173], pressure shift freezing [174], static or oscillation electric fields [175], and oscillating magnetic fields [176, 177]. Whether (electro)magnetic fields have a significant influence on nucleation is doubtful $[178,179]$. Ultrasound and pressure shift freezing have significant effects on nucleation. However, ultrasound is only effective if the frozen food is submerged in liquid as in immersion freezing. For pressure shift freezing quite specialized equipment is required, which only works for batch operations. Hence, novel technology is difficult to combine with conventional air blast freezing tunnels. I view mainly potential for ultrasound technology if applied to immersion freezing of fruits [180, 181]. Ultrasound will also enhance the heat transfer if the immersion fluid via the acoustic streaming effect.

In formulated foods like gels and ice creams, one can control nucleation also via additives, but that is difficult for fresh vegetables. Some trials are performed using pulsed electric fields, to permeate the cell membrane and to impregnate vegetables with antifreeze agents like trehalose and antifreeze proteins[155]. However, the additives can be costly.

Hence, for most foods control of ice nucleation must rather be sought in processing technologies, which can be applied with conventional freezing equipment. Examples of these technologies derive from the field of cryopreservation or freeze-drying. Examples of such methods as applied to are (1) shock freezing [19], (2) ice fog method [182], and (3) mechanical shock [49].

It is not likely that the ice fog method is applicable to vegetables and fruits because their epidermis does not permit direct contact of the liquid in the tissue and the deposited ice crystal seeds. In freeze-drying it is relatively easy to provide a mechanical shock to vials placed on the shelf of the freezer [49]. But, for belt freezing it is not evident how to apply mechanical shocks.

I view that for food processing the shock freezing method is the easiest to implement in practice. During shock freezing the product is first slowly cooled to a supercooling of about $5{ }^{\circ} \mathrm{C}$, and it is held in the supercooled state for some time. After the holding time, the freezing temperature is suddenly dropped to temperatures far below $-20{ }^{\circ} \mathrm{C}$. This temperature shock very often induces the nucleation, which is expected to give a more uniform and fine ice crystal distribution [19].

There are a few reports in food science, where the shock freezing method has shown to initiate indeed ice crystal nucleation [183-186]. The temperature shock leads to the nucleation of many small ice crystals. Due to the subsequent fast, deep freezing step the nucleated ice crystals have little time to grow and coalesce, as at low temperatures the water diffusion coefficient is too low for ice crystal growth [54]. However, a recent application of shock freezing to strawberries still shows freezing damage comparable with conventional slow freezing, despite the controlled nucleation of ice crystals [186]. The fast growth of ice crystals has caused much mechanical stress on the cell membranes and cell walls, which appears to be split in pieces similar to what happens during slicing. Apparently, the rigidity of the cell is an important factor to consider when applying shock freezing.

\section{Frozen Storage}

It is common practice that frozen foods are stored lower or equal to $-18{ }^{\circ} \mathrm{C}$, which is the limit set by legislation (such as the European directive for Quick Frozen Foods). This storage temperature is still above the glass transition for many fruits and vegetables [187]. Consequently, during frozen storage there can still be (bio)chemical activity and coarsening of ice crystals. Especially, the effects of temperature fluctuations due to the mechanical temperature control are expected to have a large impact on frozen food quality [188].

Often, it is advised for minimization of freezing damage to store foods at the intersection of freezing line and glass transition line, which lies in the range of -20 to $-40{ }^{\circ} \mathrm{C}$ for most fruits and vegetables [189]. However, one must mind that the chemical kinetics and ice coarsening are driven by diffusion, which decouples from the viscosity 
at temperatures around the glass transition [190]. Hence, the glass transition is not a good measure for diffusivity, but rather for viscosity. I have shown that near the glassy state diffusion is quite independent of the molecular weight of solutes [190]. Consequently, the effects of the chemical kinetics and ice coarsening are quite independent of the type of food, i.e., the type of solutes. But, ice coarsening can still be controlled by antifreeze proteins [191, 192], as synthesized by cold acclimation or infused via PEF.

The large independence of the type of food concerning the physical and chemical changes during storage allows for a simple strategy for improving food storage: lowering of the storage temperature will have similar effects on all stored fruits and vegetables. If the storage temperatures is lower than $-25^{\circ} \mathrm{C}$, the effect of temperature fluctuations is considerably lower due to reduced diffusion coefficients and lower (bio)chemical activitity. Of course, via packaging with good insulating properties the effects of these fluctuations can also be lowered [193].

During frozen storage, the thermal stresses accumulated during the freezing operation can relax. However, this is a very slow process with relaxation times of about half a year. The relaxation time also depends on how far the storage temperature deviates from the glass transition temperature of the frozen food $[89,194]$.

\section{Thawing}

Generally, thawing is performed more slowly than freezing. This is mainly inherently to the process for the following reasons [195]: (1) the thawed outer layer of food has a lower thermal conductivity than the frozen part, (2) the ambient temperature cannot be high, because of high temperatures promoting biochemical processes, as enzymatic activity, microbial decay or protein denaturation having adverse effects on product quality. One should mind that enzymes and microbes are often not (fully) inactivated, and proceed with their activity upon rewarming [95]. Furthermore, it is also because thawing is often left to the consumers, who either leave it in the open air in the kitchen, or in the refrigerator or immersed in tap water [195]. The latter is considerably faster, but allows solutes to leach out in the immersion liquid, but which can be minimized via having the food wrapped in plastic packaging foil [196].

On the other hand, slow thawing should give the food time to relax mechanical stresses induced by freezing and allow to reabsorb moisture, which would either be lost via drip loss [197]. The stress relaxation time is much faster in the thawed state as in frozen storage. But, for meat [198] and potato [33] it is found that thawing rate does not affect much the volume of drip loss. In general it is stated that thawing has little influence on texture, as much irreversible damage is already performed during freezing [196].
Thawing frozen food is applied in the industry if frozen food is mixed into a multi-component meal like a pizza, pie or salad [196]. Also some frozen foods are tempered, i.e., raised in temperature from -18 to $-5^{\circ} \mathrm{C}$ to allow for easy slicing [199]. Conventional thawing methods are reviewed by James [199], which rely on heat transfer via (moving) air, water or condensing steam. Via forced convection and smart temperature/time strategies the thawing can be significantly faster than at the consumer site.

Novel processing technology has been investigated for industrial thawing [200]. Thawing can be achieved via pressure-shift freezing [201], where frozen food are subject to high pressures of about $200 \mathrm{MPa}$ at $-15{ }^{\circ} \mathrm{C}$, by which the freezing point shifts. Thawing can happen at subzero temperatures, and subsequently rewarmed to room temperature. Application of this method is limited due to high costs of equipment, and their batch-like operation.

Fast thawing can also be achieved by electromagnetic means, via microwave, radio-frequency (RF) waves or ohmic heating $[170,200]$. Especially during microwave heating, there is strong non-uniform heating as the frozen part hardly absorbs microwaves. One can experience overheated edges of the food, while the inner core is still frozen.

Due to the longer wavelength of RF waves, the temperature distribution is much more uniform than with microwaves, but its non-uniformity is still limiting its application to thawing [170]. Thawing via Ohmic heating is quite promising, but it often requires immersion of the frozen food in a liquid, promoting leaching of solutes. However, the treatment times can be quite short, in the order of minutes. Thawing can also be done via ultrasonic acoustic waves, which are mainly absorbed by the frozen part. The efficient application of ultrasound requires immersion of frozen food in liquid, leading to leaching of solutes. The technique is still experimental, and still with some disadvantages like high power consumption and low penetration depth-leading to non-uniform heating [170, 200].

\section{Discussion}

\section{Summary via the Causal Network}

The above review of the effect of processing steps on the final quality of frozen vegetables and fruits is summarized by means of a causal network (also known as a concept map), cf. [202-205], as shown in Fig. 4. The (aspects of) processing steps are indicated with rectangles, which are connected to physicochemical factors of influence to the final product quality. These connectors either indicate a positive correlation (blue arrows) or a negative correlation 
Fig. 4 Causal network of how processing steps in the production chain (rectangles) impact the physicochemical factors related to final product quality. Positive correlations are indicated by blue arrows, and negative correlations are indicated by barred red lines

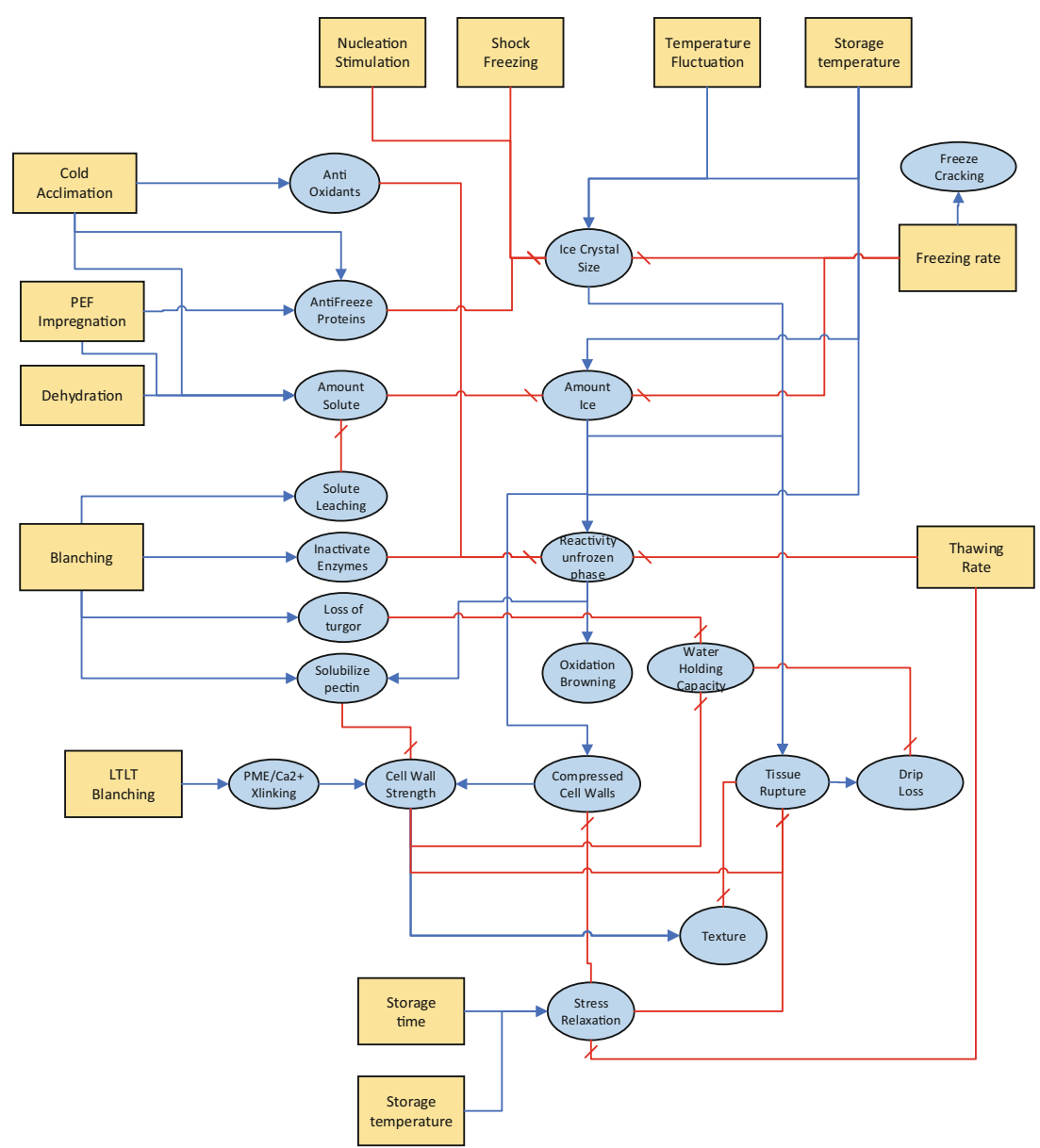

The final results are captured in Table 1. The left column lists all steps of the production chain of frozen vegetables and fruits. The next column indicates the input parameters one can adjust in these process steps. Each processing step can impact some physicochemical factors, which are stated in the third column. The fourth column indicates how the increase of the physicochemical factor in the third column impacts drip loss. This impact can either be negative (-) (decreasing drip loss), positive $(+)$, or indifferent (0). If the impact is either negative or positive, we have placed $(+/-)$ in the fourth column. In the table, the slicing operation is now incorporated.

Using the considerations from the above review and the results listed in Table 1, I have come to the following recommendations for modification of the production chain of frozen vegetables and fruits for improved drip loss:

- Perform cold storage at low temperature, just above the freezing point of the vegetable, to induce cold acclimation.

- Match the size of the product during slicing to a shorter blanching time and/or faster freezing rate.

- Match the blanching time to the size of the product and the enzyme inactivation kinetics and pectin degradation 
kinetics, i.e., perform blanching as short as possible by the use of the HTST treatment.

- Before HTST perform LTLT blanching to promote pectin cross-linking, which might be combined with calcium immersion.

- Combine dehydration and blanching via using superheated steam impingement or hot air/infrared heating.

- Find an optimal freezing rate with minimal ice crystal size, and minimal stress accumulation

- Low frozen storage temperature, $T \ll-18{ }^{\circ} \mathrm{C}$, to reduce Ostwald ripening and the product sensitivity to temperature fluctuations.

- Improve packaging during frozen storage, with increased thermal insulation and moisture barrier, for minimization effects of temperature fluctuations.

- Perform thawing at moderate temperature (0-10 degrees) and allow time for stress relaxation and resorption of drip loss.

From the list above, one can observe there are largely two main strategies to reduce drip loss: (1) improved freezing operations, with faster freezing rates and lower freezing temperatures, and (2) the increase of solute concentrations before freezing, which is achieved via other processing steps prior to freezing. However, one must also consider the adverse effects of increased solute concentration (i.e., reduced water content) on other quality factors like texture or water holding capacity/juiciness. It is clear that industry has to make a compromise between different quality traits.

\section{Process Intensification and Production Chain Optimization}

Above, I have discussed the individual processing steps in the production chain. Here, I discuss potential improvements if larger parts or the complete product chain is taken into consideration. First, I discuss the possibilities of process intensification, where one tries to integrate several unit operations into a new one. In the production chain of frozen foods, there are opportunities for process intensification, if there are subsequent processing steps which use the same medium for heat transfer. Via combining such processing steps one shortens the residence time, often leading to improving final product quality. From this perspective, I see two possibilities for process intensification: (1) combination of blanching and dehydration of vegetables if performed in hot air or (superheated) steam and (2) combination of osmotic dehydration and freezing for fruits if immersed in a liquid.

If the blanching is performed in air or steam, there is little leaching of solutes and nutrients. This dry blanching is easily combined with dehydration, which can be viewed as the first step in dehydrofreezing. However, dehydration can lead to loss of texture, if there is structural collapse of the tissue [27]. Volumetric heating can help in preventing collapse during dehydration due to the generation of pressure inside the tissue due to internal evaporation [27]. Another suggested measure to reduce texture loss is to strengthen the cell wall via PME-enhanced cross-linking of pectin with $\mathrm{Ca}^{2+}$, as in the LTLT blanching method. The dehydration/blanching step should be designed such that the reduction in texture breakdown in the following freezing step significantly outweighs the texture loss imposed by the dehydration. Recall, that dehydrated vegetables will have less freezing damage due to a reduced ice crystal size, and a reduced amount of ice formation.

The other possibility for process intensification is foreseen for fruits, that are immersed in osmotic solutions, to perform both osmotic dehydration and immersion freezing [167]. There is good potential to combine it with novel technology. Mild PEF treatments can make the cell membrane more permeable but can be repaired if the cells remain viable [150]. Furthermore, thanks to the immersion liquid ultrasound can be applied efficiently to promote ice nucleation [173]. This possibility for process intensification offers opportunity for fruits, where the conventional freezing process leads to too much freezing damage due to their fragile tissue, such as strawberries. Still, the design of the intensified process should be done with care to overcome the two drawbacks of immersion freezing [167]: (a) to keep the immersion liquid free from microbial contamination and (b) the influx of solutes from the immersion liquid into the fruit. The latter can affect the health impact of the fruit, due to the increase in sugar levels. However, this might be solved by the use of polyols as the osmolyte [145].

Next to process intensification, whose implementation is still quite involving for the food industry, I view there are still ample opportunities for simultaneous optimization of the complete production chain. Taking into account the interaction between various processing steps, one could optimize the settings of each processing step for the optimal value of the final product quality.

This optimization requires good quantitative knowledge on how the processing impacts the product quality. Over the years a large body of knowledge on this matter is generated, but still, some knowledge is lacking especially the impact of processing on mechanical damage and water holding properties. Below, I will summarize some of the findings, that can be found in literature. Most of this knowledge is on the kinetics on biochemical processes impacting product quality, which links to the functionality of several processing steps like blanching and freezing, i.e., to lower the activity of these biochemical processes. For optimizing the production chain for the final quality one has to minimize the thermal impact of the processing steps. This can be achieved via matching the time scale and/or resi- 
dence time of the thermal processing with the time scale of biochemical kinetics. Below, we discuss the time scales of relevant biochemical processes in several processing steps.

Cold acclimation happens at relatively long time scales of several weeks [104]. Hence, to invoke cold acclimation, one has to match cold storage times of freshly harvested vegetables and fruits to this long time scale of cold acclimation. Diurnal fluctuating storage temperatures can help to shorten this time scale, as the metabolism is higher at elevated temperatures.

Blanching affects the inactivation of enzymes, the degradation of color and simultaneously modifies the cell wall structure. These kinetics have been investigated for several vegetables [212-216]. The cell wall structure is modified enzymatically via the PME enzyme, and via $\beta$-elimination. PME removes methoxy side groups from pectin, which makes them less vulnerable to $\beta$-elimination. The interaction between these processes is captured in the model by Verlinden [214]. The time scale of the heat transfer process can be estimated with simple models, as proposed earlier [217, 218]. The time scale of the heat transfer depends on (1) the size of the product, (2) the external heat resistance as quantified by the heat transfer coefficient $h$, and (3) the internal heat resistance. For determining the endpoint of blanching the limiting time scale of the most important biochemical processes has to match the time scale of heat transfer [219].

Blanching modifies the mass transfer during a subsequent dehydration step, due to the permeation of the cell membranes, allowing faster diffusion of moisture during drying.[220]. Even blanching enhances the mass transfer during osmotic dehydration, but induces loss of cell membrane integrity. But, this makes the purpose of osmotic dehydration obsolete, which is to remove moisture, while maintaining turgor and cell membrane integrity [221]. For conventional dehydration methods like air drying or via superheated steam it is very beneficial to apply blanching beforehand due to the enhancement of the mass transfer. During dehydration the time scale for mass transfer is usually much longer than the time scale for heating. However, the time scale for mass transfer can still be computed using a similar approach as used for heat transfer [217, 218]. But, it requires knowledge of moisture diffusion coefficients, for which predictive theories are at hand [190, 222, 223].

The time scale for the freezing operation can be estimated using the Planck method, as detailed in [53]. With the help of the freezing time, and the difference between initial freezing point and coolant temperature (or desired final product temperature), and thermal conductivity [224] one can compute the freezing rate. Knowing the freezing rate one can estimate the ice crystal size via a power-law [53]. The ice crystal size can be taken as a measure for freezing damage [62].
During frozen storage, there can be further recrystallization, i.e., ice coarsening via Ostwald ripening. For sugar solutions, which can be regarded as a model system for fruits, a study has been performed concerning the kinetics [56]. The growth rate of the ice crystal volume is linear with the diffusion coefficient of water [225], which is known for carbohydrate solutions [190]. The model shows that the diffusion coefficient depends on temperature and mass fraction of water. Hence, recrystallization is minimized at lower storage temperatures, which lowers both the diffusion coefficient and the mass fraction of water (due to progressed ice fraction). For computing the ice fraction and the remaining water fraction in the unfrozen phase a simple relation with the storage temperature and initial freezing point can be used [224, 226].

\section{Conclusions}

In this paper, I have reviewed the production of frozen vegetables and fruits from a chain perspective, which is instigated by our experience with industrial projects that final product quality can significantly be improved via optimization of the complete production chain [205].

This optimization requires good knowledge of the fundamental physicochemical and biochemical processes underlying the changes in product quality during their processing in the production chain. This knowledge is summarized in a network diagram, showing the causal relations between processing steps and physicochemical factors impacting various quality aspects. The use of the causal network is shown for the example of drip loss, an important final product quality.

In general, it is found that it is difficult to implement novel processing technology in current production chains. But, I do see opportunities for the use of novel processing technology if combined with process intensification, where several unit operations can be combined into a new single operation. In particular, I see the potential for combining blanching and dehydration for vegetables or combining osmotic dehydration and immersion freezing for fruits. But, the implementation of process intensification can still be quite involving modification of existing production chains.

Still, I view there is an opportunity to improve final quality of frozen food via optimization of the existing production chain, via careful matching the processing times to the time scales of the fundamental physicochemical and biochemical processes. For this optimization the causal network can be a good guiding tool.

Funding Information The author has received funding for this review as part of the PPS Tasty Sustainable Frozen Foods, which was cofinanced by the Dutch Ministry of Economic Affairs; the project is registered under contract number TKI-AG-15235. 
Open Access This article is licensed under a Creative Commons Attribution 4.0 International License, which permits use, sharing, adaptation, distribution and reproduction in any medium or format, as long as you give appropriate credit to the original author(s) and the source, provide a link to the Creative Commons licence, and indicate if changes were made. The images or other third party material in this article are included in the article's Creative Commons licence, unless indicated otherwise in a credit line to the material. If material is not included in the article's Creative Commons licence and your intended use is not permitted by statutory regulation or exceeds the permitted use, you will need to obtain permission directly from the copyright holder. To view a copy of this licence, visit http://creativecommons. org/licenses/by/4.0/.

\section{References}

1. Silva CLM, Gonċalves EM, Brandao TRS (2008) Freezing of fruits and vegetables. Frozen food science and technology, pp 165

2. Zheng L, Sun DW (2006) Innovative applications of power ultrasound during food freezing processes-a review. Trends in Food Science \& Technology 17(1):16-23

3. Tassou SA, Lewis JS, Ge YT, Hadawey A, Chaer I (2010) A review of emerging technologies for food refrigeration applications. Appl Therm Eng 30(4):263-276

4. Cheng X, Zhang M, Xu B, Adhikari B, Sun J (2015) The principles of ultrasound and its application in freezing related processes of food materials: a review. Ultrasonics sonochemistry 27:576-585

5. James C, Purnell G, James SJ (2015) A review of novel and innovative food freezing technologies. Food and Bioprocess Technology 8(8):1616-1634

6. Cheng L, Sun DW, Zhu Z, Zhang Z (2017) Emerging techniques for assisting and accelerating food freezing processes: a review of recent research progresses. Critical reviews in food science and nutrition 57(4):769-781

7. Xin Y, Zhang M, Xu B, Adhikari B, Sun J (2015) Research trends in selected blanching pretreatments and quick freezing technologies as applied in fruits and vegetables: a review. International Journal of Refrigeration 57:11-25

8. Neri L, Hernando I, Pérez-Munuera I, Sacchetti G, Mastrocola D, Pittia P (2014) Mechanical properties and microstructure of frozen carrots during storage as affected by blanching in water and sugar solutions. Food chemistry 144:65-73

9. Banasik A, Kanellopoulos A, Claassen GDH, BloemhofRuwaard JM, van der Vorst GAJ (2017) Assessing alternative production options for eco-efficient food supply chains using multi-objective optimization. Ann Oper Res 250(2):341-362

10. Gómez F, Sjöholm I (2004) Applying biochemical and physiological principles in the industrial freezing of vegetables: a case study on carrots. Trends in Food Science \& Technology 15(1):39-43

11. Chan WS, Toledo RT (1976) Dynamics of freezing and their effects on the water-holding capacity of a gelatinized starch gel. J Food Sci 41(2):301-303

12. Sikorski ZE (1978) Protein changes in muscle foods due to freezing and frozen storage. Int J Refrig 1(3):173-180

13. Wagner JR, Anon MC (1985) Effect of freezing rate on the denaturation of myofibrillar proteins. International Journal of Food Science and Technology 20(6):735-744

14. Ngapo TM, Babare IH, Reynolds J, Mawson RF (1999) Freezing and thawing rate effects on drip loss from samples of pork. Meat Sci 53(3):149-158
15. Leygonie C, Britz TJ, Hoffman LC (2012) Impact of freezing and thawing on the quality of meat. Meat science 91(2):93-98

16. Blakesley D, Al-Mazrooei S, Henshaw GG (1995) Cryopreservation of embryogenic tissue of sweet potato (Ipomoea batatas): use of sucrose and dehydration for cryoprotection. Plant cell reports 15(3-4):259-263

17. Benson EE (2008) Cryopreservation theory. In: Plant cryopreservation: a practical guide, pages $15-32$. Springer

18. Kaczmarczyk A, Funnekotter B, Menon A, Phang PY, AlHanbali A, Bunn E, Mancera RL (2012) Current issues in plant cryopreservation. In: Current frontiers in cryobiology. InTech

19. Morris GJ, Acton E (2013) Controlled ice nucleation in cryopreservation-a review. Cryobiology 66(2):85-92

20. Guy CL (1990) Cold acclimation and freezing stress tolerance: role of protein metabolism. Annual review of plant biology 41(1):187-223

21. Roger SP (2001) Plant freezing and damage. Ann Bot 87(4):417424

22. Yamada T, Kuroda K, Jitsuyama Y, Takezawa D, Arakawa K, Fujikawam S (2002) Roles of the plasma membrane and the cell wall in the responses of plant cells to freezing. Planta 215(5):770-778

23. Ball MC, Canny MJ, Huang CX, Heady RD (2004) Structural changes in acclimated and unacclimated leaves during freezing and thawing. Funct Plant Biol 31(1):29-40

24. Hincha DK, Zuther Ellen (2014) Introduction: plant cold acclimation and freezing tolerance. In: Plant cold acclimation, pages $1-6$. Springer

25. Piotr PL (1998) Effect of pre-drying treatment, drying and rehydration on plant tissue properties: a review. International Journal of Food Properties 1(1):1-22

26. Lewicki PP, Pawlak G (2003) Effect of drying on microstructure of plant tissue. Drying technology 21(4):657-683

27. Prothon F, Ahrné L, Sjöholm I (2003) Mechanisms and prevention of plant tissue collapse during dehydration: a critical review

28. Ickes L, Welti A, Hoose C, Lohmann U (2015) Classical nucleation theory of homogeneous freezing of water: thermodynamic and kinetic parameters. Physical Chemistry Chemical Physics 17(8):5514-5537

29. James Christian, Seignemartin Violaine, James StephenJ (2009) The freezing and supercooling of garlic (Allium sativum L.) Int J Refrig 32(2):253-260

30. James C, Hanser P, James SJ (2011) Super-cooling phenomena in fruits, vegetables and seafoods. In: 11th International Congress on Engineering and Food (ICEF 2011), Athens, Greece, pp 22-26

31. Martins RC, Lopes VV (2007) Modelling supercooling in frozen strawberries: experimental analysis, cellular automation and inverse problem methodology. J Food Eng 80(1):126-141

32. Cox DR, Moore SR (1999)

33. Wickramasinghe AE (2014) Influence of freezing and thawing methods on textural quality of thawed frozen potato slices. $\mathrm{PhD}$ thesis, The Ohio State University

34. Osato M, Toru A, Toshimasa Y (1992) Freezing and ice structure formed in protein gels. Bioscience, biotechnology, and biochemistry 56(6):953-957

35. Osato M, Tomoyuki F, Yoko S (2007) Analysis of ice structure formed in frozen agar gel. Food science and technology research 10(4):437-441

36. Sarkar A, Singh RP (2004) Modeling flow and heat transfer during freezing of foods in forced airstreams. Journal of food science 69(9):E488-E496

37. Harnkarnsujarit N, Charoenrein S, Roos Y (2012) Microstructure formation of maltodextrin and sugar matrices in freeze-dried systems. Carbohydrate polymers 88(2):734-742 
38. Sanguansri C, Nutsuda P (2010) Undercooling associated with slow freezing and its influence on the microstructure and properties of rice starch gels. Journal of Food Engineering $100(2): 310-314$

39. Koop T, Luo B, Tsias A, Peter T (2000) Water activity as the determinant for homogeneous ice nucleation in aqueous solutions. Nature 406(6796):611

40. Van der Sman RGM, Boer E (2005) Predicting the initial freezing point and water activity of meat products from composition data. J Food Eng 66(4):469-475

41. Van der Sman RGM, Meinders MBJ (2011) Prediction of the state diagram of starch water mixtures using the Flory-Huggins free volume theory. Soft Matter 7(2):429-442

42. Zobrist B, Marcolli C, Koop T, Luo BP, Murphy DM, Lohmann U, Zardini AA, Krieger UK, Corti T, Cziczo DJ, et al. (2006) Oxalic acid as a heterogeneous ice nucleus in the upper troposphere and its indirect aerosol effect. Atmos Chem Phys 6(10):3115-3129

43. Blond G (1985) Freezing in polymer-water systems and properties of water. In: Properties of water in foods, pages 531-542. Springer

44. Sanguansri C, Goddard M, Reid DS (1991) Effect of solute on the nucleation and propagation of ice. In: Water relationships in foods, pages 191-198. Springer

45. Reid DS (1993) Basic physical phenomena in the freezing and thawing of plant and animal tissues. Frozen food technology, 1-19

46. Zobrist B, Marcolli C, Peter T, Koop T (2008) Heterogeneous ice nucleation in aqueous solutions: the role of water activity. The Journal of Physical Chemistry A 112(17):3965-3975

47. MacLeod CS, McKittrick JA, Hindmarsh JP, Johns ML, Wilson DI (2006) Fundamentals of spray freezing of instant coffee. Journal of food engineering 74(4):451-461

48. Huang H, Yarmush ML, Usta OB (2018) Long-term deep supercooling of large-volume water via surface sealing with immiscible liquids. arXiv preprint arXiv 1803:08914

49. Geidobler R, Winter G (2013) Controlled ice nucleation in the field of freeze-drying: fundamentals and technology review. Eur J Pharm Biopharm 85(2):214-222

50. Gusta LawrenceV, Wisniewski Michael (2013) Understanding plant cold hardiness: an opinion. Physiol Plant 147(1):4-14

51. Richelle C, Prickett L, Marquez-Curtis A, Elliott JA, McGann LE (2015) Effect of supercooling and cell volume on intracellular ice formation. Cryobiology 70(2):156-163

52. James C, Purnell G, James SJ (2014) A critical review of dehydrofreezing of fruits and vegetables. Food and bioprocess technology 7(5):1219-1234

53. Van der Sman RGM, Voda A, van Dalen G, Duijster A (2013) Ice crystal interspacing in frozen foods. J Food Eng 116(2):622626

54. van der Sman RGM (2016) Phase field simulations of ice crystal growth in sugar solutions. Int J Heat Mass Transfer 95:153-161

55. Xu XL, Liu F (2014) Crystal growth due to recrystallization upon annealing rapid solidification microstructures of deeply undercooled single phase alloys quenched before recalescence. Crystal Growth \& Design 14(5):2110-2114

56. Sutton RL, Lips A, Piccirillo G, Sztehlo A (1996) Kinetics of ice recrystallization in aqueous fructose solutions. Journal of food science 61(4):741-745

57. Sutton RL, Lips A, Piccirillo G (1996) Recrystallization of aqueous fructose solutions as affected by locust bean gum. Journal of food science 61(4):746-748

58. Ablett S, Clarke CJ, Izzard MJ, Martin DR (2002) Relationship between ice recrystallisation rates and the glass transition in frozen sugar solutions. Journal of the Science of Food and Agriculture 82(15):1855-1859
59. Regand A, Douglas Goff H (2003) Structure and ice recrystallization in frozen stabilized ice cream model systems. Food hydrocolloids 17(1):95-102

60. Victor Vicent, Ndoye F-T, Verboven P, Nicolaï B, Alvarez $G$ (2019) Effect of dynamic storage temperatures on the microstructure of frozen carrot imaged using X-ray micro-CT. J Food Eng 246:232-241

61. Soukoulis C, Fisk I (2016) Innovative ingredients and emerging technologies for controlling ice recrystallization, texture, and structure stability in frozen dairy desserts: a review. Critical reviews in food science and nutrition 56(15):2543-2559

62. Reid DS (1997) Overview of physical/chemical aspects of freezing. In: Quality in frozen food, pages 10-28. Springer

63. Crapiste GH, Whitaker S, Rotstein E (1988) Drying of cellular material-I. a mass transfer theory. Chem Eng Sci 43(11):29192928

64. Kunzek H, Kabbert R, Gloyna D (1999) Aspects of material science in food processing: changes in plant cell walls of fruits and vegetables. Zeitschrift für Lebensmitteluntersuchung undForschung A 208(4):233-250

65. Van der Sman RGM (2015) Hyperelastic models for hydration of cellular tissue. Soft matter 11(38):7579-7591

66. Van der Sman RGM, Paudel E, Voda A, Khalloufi S (2013) Hydration properties of vegetable foods explained by FloryRehner theory. Food research international 54(1):804-811

67. Ekaraj Paudel, Boom RM, van Haaren E, Siccama J, Ruud GM, van der S (2016) Effects of cellular structure and cell wall components on water holding capacity of mushrooms. Journal of Food Engineering 187:106-113

68. Brannon-Peppas L, Peppas NA (1991) Equilibrium swelling behavior of pH-sensitive hydrogels. Chem Eng Sci 46(3):715-722

69. English AE, Tanaka T, Edelman ER (1996) Polyelectrolyte hydrogel instabilities in ionic solutions. The Journal of chemical physics 105(23):10606-10613

70. Voda A, Homan N, Witek M, Duijster A, Dalen GV, Sman RVD, Nijsse J, Vliet LV, As HV, Duynhoven JV (2012) The impact of freeze-drying on microstructure and rehydration properties of carrot. Food Res Int 49(2):687-693

71. Mazur P (1984) Freezing of living cells: mechanisms and implications. American Journal of Physiology-Cell Physiology 247(3):C125-C142

72. Arora R (2018) Mechanism of freeze-thaw injury and recovery: a cool retrospective and warming up to new ideas. Plant science: an international journal of experimental plant biology 270:301

73. Rajashekar CB, Burke MJ (1996) Freezing characteristics of rigid plant tissues (development of cell tension during extracellular freezing). Plant Physiol 111(2):597-603

74. Wisniewski M, Gusta L, Neuner G (2014) Adaptive mechanisms of freeze avoidance in plants: a brief update. Environmental and Experimental Botany 99:133-140

75. Yamaki S (1984) Isolation of vacuoles from immature apple fruit flesh and compartmentation of sugars, organic acids, phenolic compounds and amino acids. Plant Cell Physiol 25(1):151-166

76. Joslyn MA (1949) Enzyme activity in frozen vegetable tissue. Adv Enzymol Relat Areas Mol Biol 9:613-652

77. Cano MP, De Ancos B, Lobo G (1995) Peroxidase and polyphenoloxidase activities in papaya during postharvest ripening and after freezing/thawing. J Food Sci 60(4):815-817

78. Bahćeci KS, Serpen A, Gökmen V, Acar J (2005) Study of lipoxygenase and peroxidase as indicator enzymes in green beans: change of enzyme activity, ascorbic acid and chlorophylls during frozen storage. J Food Eng 66(2):187-192

79. Steinbuch E (1976) Improvement of texture of frozen vegetables by stepwise blanching treatments. International Journal of Food Science and Technology 11(3):313-316 
80. Lin Z, Schyvens E (1995) Influence of blanching treatments on the texture and color of some processed vegetables and fruits. Journal of food processing and preservation 19(6):451-465

81. Li NI, Lin D, Barrett DM (2005) Pectin methylesterase catalyzed firming effects on low temperature blanched vegetables. Journal of food engineering 70(4):546-556

82. Van Buggenhout S, Sila DN, Duvetter T, van Loey A, Hendrickx M (2009) Pectins in processed fruits and vegetables: part IIItexture engineering. Comprehensive Reviews in Food Science and Food Safety 8(2):105-117

83. Ancos BD, González EM, Pilar Cano M (2000) Ellagic acid, vitamin $\mathrm{C}$, and total phenolic contents and radical scavenging capacity affected by freezing and frozen storage in raspberry fruit. Journal of agricultural and food chemistry 48(10):45654570

84. Szymońska J, Krok F, Tomasik P (2000) Deep-freezing of potato starch. Int J Biol Macromol 27(4):307-314

85. Álvarez DM, Fernández C, Canet W (2005) Effect of freezing/thawing conditions and long-term frozen storage on the quality of mashed potatoes. Journal of the Science of Food and Agriculture 85(14):2327-2340

86. Shifeng YU, Ma Y, Sun D-W (2010) Effects of freezing rates on starch retrogradation and textural properties of cooked rice during storage. LWT-Food Science and Technology 43(7):11381143

87. Charoenrein S, Harnkarnsujarit N (2017) Food freezing and non-equilibrium states. In: Non-equilibrium states and glass transitions in foods, pages 39-62. Elsevier

88. Chaves A, Zaritzky N (2018) Cooling and freezing of fruits and fruit products. In: Fruit preservation, pages 127-180. Springer

89. Shi X, Datta AK, Mukherjee Y (1998) Thermal stresses from large volumetric expansion during freezing of biomaterials. Journal of biomechanical engineering 120(6):720-726

90. Tuan Pham Q, Bail AL, Tremeac B (2006) Analysis of stresses during the freezing of solid spherical foods. International journal of refrigeration 29(1):125-133

91. Tuan Pham Q, Bail AL, Hayert M, Tremeac B (2005) Stresses and cracking in freezing spherical foods: a numerical model. Journal of food engineering 71(4):408-418

92. Schäfer AT, Kaufmann JD (1999) What happens in freezing bodies?: experimental study of histological tissue change caused by freezing injuries. Forensic science international 102(23): $149-158$

93. Tao D, Li PH, Carter JV (1983) Role of cell wall in freezing tolerance of cultured potato cells and their protoplasts. Physiol Plant 58(4):527-532

94. Fujikawa S, Jitsuyama Y, Kuroda K (1999) Determination of the role of cold acclimation-induced diverse changes in plant cells from the viewpoint of avoidance of freezing injury. J Plant Res 112(2):237-244

95. Phothiset S, Charoenrein S (2014) Effects of freezing and thawing on texture, microstructure and cell wall composition changes in papaya tissues. Journal of the Science of Food and Agriculture 94(2):189-196

96. Chassagne-Berces S, Poirier C, Devaux M-F, Fonseca F, Lahaye M, Pigorini G, Girault C, Marin M, Guillon F (2009) Changes in texture, cellular structure and cell wall composition in apple tissue as a result of freezing. Food Res Int 42(7):788-797

97. Bengtsson BL, Lindberg P (1985) Process of preparing frozen fruit or vegetables, October 15 US Patent 4,547,380

98. Lamaire B, Lamaire J, Lamaire B (2016)

99. Hastings JJ (2017) A process apparatus and system for treating fruits or vegetables, February 9

100. Alexandre E, Brandão TRS, Silva CLM (2013) Frozen food and technology. Advances in Food Science and Technology, 123-150
101. Agblor A, Scanlon MG (2000) Processing conditions influencing the physical properties of french fried potatoes. Potato research 43(2):163-177

102. Paull RE (1999) Effect of temperature and relative humidity on fresh commodity quality. Postharvest biology and technology 15(3):263-277

103. Jackman RL, Yada RY, Marangoni A, Parkin KL, Stanley DW (1988) Chilling injury. a review of quality aspects. Journal of food quality 11(4):253-278

104. FG Galindo I, Sjöholm AG, Rasmusson SW, Kaack K (2007) Plant stress physiology: opportunities and challenges for the food industry. Critical reviews in food science and nutrition 47(8):749

105. Bonat Celli G, Ghanem A, Su-Ling Brooks M (2016) Influence of freezing process and frozen storage on the quality of fruits and fruit products. Food Reviews International 32(3):280-304

106. Demir E, Dymek K, Galindo FG (2018) Technology allowing baby spinach leaves to acquire freezing tolerance. Food and bioprocess technology 11(4):809-817

107. Wisniewski M, Fuller M (1999) Ice nucleation and deep supercooling in plants: new insights using infrared thermography. In: Cold-adapted organisms, pages 105-118. Springer

108. Toivonen PMA, Brummell DA (2008) Biochemical bases of appearance and texture changes in fresh-cut fruit and vegetables. Postharvest biology and technology 48(1):1-14

109. Mishra BB, Gautam S, Sharma A (2012) Browning of fresh-cut eggplant: impact of cutting and storage. Postharvest Biology and Technology 67:44-51

110. Van de Velde F, Fenoglio C, Piagentini AM, Pirovani ME (2018) Modeling the impact of the type of cutting and storage temperature on the bioactive compound content, phenylpropanoid metabolism enzymes and quality attributes of fresh-cut strawberries. Food and bioprocess technology 11(1):96-109

111. Kirtil E, Oztop MH, Sirijariyawat A, Ngamchuachit P, Barrett DM, McCarthy MJ (2014) Effect of pectin methyl esterase (PME) and $\mathrm{CaCl} 2$ infusion on the cell integrity of fresh-cut and frozen-thawed mangoes: an NMR relaxometry study. Food research international 66:409-416

112. Toepfl S, Siemer C, Heinz V (2014) Effect of high-intensity electric field pulses on solid foods. In: Emerging technologies for food processing, pages 147-154. Elsevier

113. Botero-Uribe M, Fitzgerald M, Gilbert RG, Midgley J (2017) Effect of pulsed electrical fields on the structural properties that affect french fry texture during processing. Trends in food science \& technology 67:1-11

114. Leong SY, Richter LK, Knorr D, Oey I (2014) Feasibility of using pulsed electric field processing to inactivate enzymes and reduce the cutting force of carrot (Daucus carota var. Nantes). Innovative food science \& emerging technologies 26:159-167

115. Soliva-Fortuny R, Balasa A, Knorr D, Martín-Belloso O (2009) Effects of pulsed electric fields on bioactive compounds in foods: a review. Trends in Food Science and Technology 20(1112):544-556

116. Günes B, Bayindirli A (1993) Peroxidase and lipoxygenase inactivation during blanching of green beans, green peas and carrots. LWT-Food Science and Technology 26(5):406-410

117. Gökmen V, Bahćeci KS, Serpen A, Acar J (2005) Study of lipoxygenase and peroxidase as blanching indicator enzymes in peas: change of enzyme activity, ascorbic acid and chlorophylls during frozen storage. LWT-Food Science and Technology 38(8):903-908

118. Severini C, Baiano A, De Pilli T, Romaniello R, Derossi A (2003) Prevention of enzymatic browning in sliced potatoes by blanching in boiling saline solutions. LWT-Food Science and Technology 36(7):657-665

119. Guida V, Ferrari G, Pataro G, Chambery A, Di Maro A, Parente A (2013) The effects of ohmic and conventional blanching on the 
nutritional, bioactive compounds and quality parameters of artichoke heads. LWT-Food Science and Technology 53(2):569-579

120. Galindo FG, Toledo RT, Sjöholm I (2005) Tissue damage in heated carrot slices. comparing mild hot water blanching and infrared heating. Journal of food engineering 67(4):381-385

121. Alzamora SM, Gerschenson LN, Vidales SL, Nieto A (2000) Structural changes in the minimal processing of fruits: some effects of blanching and sugar impregnation. Food engineering 1997:117-139

122. Quenzer NM, Burns EE (1981) Effects of microwave, steam and water blanching on freeze-dried spinach. J Food Sci 46(2):410 413

123. Zhang Q, Cavalieri RP (1991) Thermal model for steam blanching of green beans and determination of surface heat transfer coefficient. Transactions of the ASAE 34(1):182-0186

124. Xiao HW, Bai JW, Sun DW, Gao ZJ (2014) The application of superheated steam impingement blanching (SSIB) in agricultural products processing-a review. J Food Eng 132:39-47

125. Alfy A, Kiran BV, Jeevitha GC, Hebbar HU (2016) Recent developments in superheated steam processing of foods-a review. Critical reviews in food science and nutrition 56(13):2191-2208

126. Stanley DW, Bourne MC, Stone AP, Wismer WV (1995) Low temperature blanching effects on chemistry, firmness and structure of canned green beans and carrots. J Food Sci 60(2):327-333

127. Drake SR, Carmichael DM (1986) Frozen vegetable quality as influenced by high temperature short time (HTST) steam blanching. Journal of food science 51(5):1378-1379

128. Roy SS, Taylor TA, Kramer HL (2001) Textural and ultrastructural changes in carrot tissue as affected by blanching and freezing. J Food Sci 66(1):176-180

129. Sila DN, Smout C, Elliot F, van Loey A, Hendrickx M (2006) Non-enzymatic depolymerization of carrot pectin: toward a better understanding of carrot texture during thermal processing. Journal of Food Science 71(1):E1-E9

130. Canet W, Alvarez MD, Luna P, Fernandez C, Tortosa ME (2005) Blanching effects on chemistry, quality and structure of green beans (cv. Moncayo). European food research \& technology 220(3-4):421-430

131. Quintero-Ramos A, Bourne M, Barnard J, Gonzalez-Laredo R, Anzaldua-Morales A, Pensaben-Esquivel M, Marquez-Melendez $\mathrm{R}$ (2002) Low temperature blanching of frozen carrots with calcium chloride solutions at different holding times on texture of frozen carrots. Journal of food processing and preservation 26(5):361-374

132. Neri L, Hernando IH, Pérez-Munuera I, Sacchetti G, Pittia P (2011) Effect of blanching in water and sugar solutions on texture and microstructure of sliced carrots. Journal of food science 76(1):E23-E30

133. Verlinden BE, De Baerdemaeker J (1997) Modeling low temperature blanched carrot firmness based on heat induced processes and enzyme activity. Journal of food science 62(2):213-219

134. Ramesh MN, Wolf W, Tevini D, Bognar A (2002) Microwave blanching of vegetables. J Food Sci 67(1):390-398

135. Zhang Z, Guo C, T Gao HFu, Chen Q, Wang Y (2018) Pilot-scale radiofrequency blanching of potato cuboids: heating uniformity. J Sci Food Agric 98(1):312-320

136. Yu XL, Ju HY, Mujumdar AS, Zheng ZA, Wang J, Deng LZ, Gao ZJ, Xiao HW (2019) Experimental and simulation studies of heat transfer in high-humidity hot air impingement blanching (hhaib) of carrot. Food and bioproducts processing 114:196204

137. Liu ZL, Bai JW, Yang WX, Wang J, LZ Deng XLYu, Zheng ZA, Gao ZJ, Xiao HW (2019) Effect of high-humidity hot air impingement blanching (HHAIB) and drying parameters on drying characteristics and quality of broccoli florets. Drying Technology 37(10):1251-1264
138. Al-Khuseibi MK, Sablani SS, Perera CO (2005) Comparison of water blanching and high hydrostatic pressure effects on drying kinetics and quality of potato. Dry Technol 23(12):2449-2461

139. Castro SM, Saraiva JA, Lopes-da Silva JA, Delgadillo I, van Loey A, Smout C, Hendrickx M (2008) Effect of thermal blanching and of high pressure treatments on sweet green and red bell pepper fruits (Capsicum annuum L.) Food chemistry 107(4):1436-1449

140. Wu B, Pan Z, Qu W, Wang B, Wang J, Ma H (2014) Effect of simultaneous infrared dry-blanching and dehydration on quality characteristics of carrot slices. LWT-Food Science and Technology 57(1):90-98

141. Gong C, Zhao Y, Zhang H, Yue J, Miao Y, Jiao S (2019) Investigation of radio frequency heating as a dry-blanching method for carrot cubes. Journal of food engineering 245:5356

142. Gong C, Zhang H, Yue J, Miao Y, Jiao S (2019) Investigation of hot air-assisted radio frequency heating as a simultaneous dryblanching and pre-drying method for carrot cubes. Innovative Food Science \& Emerging Technologies 102181:56

143. Ando Y, Maeda Y, Mizutani K, Wakatsuki N, Hagiwara S, Nabetani H (2016) Effect of air-dehydration pretreatment before freezing on the electrical impedance characteristics and texture of carrots. J Food Eng 169:114-121

144. Raoult-Wack AL (1994) Recent advances in the osmotic dehydration of foods. Trends in Food Science \& Technology 5(8):255-260

145. Kowalska H, Woźniak L, Masiarz E, Stelmach A, Salamon A, Kowalska J, Piotrowski D, Marzec A (2019) The impact of using polyols as osmotic agents on mass exchange during osmotic dehydration and their content in osmodehydrated and dried apples. Dry Technol, 1-12. https://doi.org/10.1080/ 07373937.2019.1653319

146. Rastogi NK, Raghavarao KSMS, Niranjan K, Knorr D (2002) Recent developments in osmotic dehydration: methods to enhance mass transfer. Trends in Food Science \& Technology 13(2):48-59

147. Mille Y, Beney L, Gervais P (2002) Viability of escherichia coli after combined osmotic and thermal treatment: a plasma membrane implication. Biochimica et Biophysica Acta (BBA)Biomembranes 1567:41-48

148. Pham QT (2008) Advances in food freezing/thawing/freeze concentration modelling and techniques. Japan Journal of Food Engineering 9(1):21-32

149. Fito P, Chiralt A, Betoret N, Gras M, Cháfer M, MartınezMonzó J, Andrés A, Vidal D (2001) Vacuum impregnation and osmotic dehydration in matrix engineering: application in functional fresh food development. Journal of Food Engineering 49(2-3):175-183

150. Velickova E, Tylewicz U, Dalla Rosa M, Winkelhausen E, Kuzmanova S, Romani S (2018) Effect of pulsed electric field coupled with vacuum infusion on quality parameters of frozen/thawed strawberries. J Food Eng 233:57-64

151. Van Buggenhout $S$, Grauwet $T$, van Loey A, Hendrickx M (2008) Structure/processing relation of vacuum infused strawberry tissue frozen under different conditions. European Food Research and Technology 226(3):437-448

152. Shayanfar S, Chauhan OP, Toepfl S, Heinz V (2014) Pulsed electric field treatment prior to freezing carrot discs significantly maintains their initial quality parameters after thawing. International Journal of Food Science \& Technology 49(4):12241230

153. Galindo FG, Dymek K (2016) Pulsed electric fields in combination with vacuum impregnation for improving freezing tolerance of vegetables. Handbook of Electroporation, pp 1-17. https://doi.org/10.1007/978-3-319-32886-7_32 
154. Phoon PY, Galindo FG, Vicente A, Dejmek P (2008) Pulsed electric field in combination with vacuum impregnation with trehalose improves the freezing tolerance of spinach leaves. Journal of Food Engineering 88(1):144-148

155. Dymek K, Dejmek P, Galindo FG, Wisniewski M (2015) Influence of vacuum impregnation and pulsed electric field on the freezing temperature and ice propagation rates of spinach leaves. LWT-Food Science and Technology 64(1):497-502

156. Wiktor A, Schulz M, Voigt E, Witrowa-Rajchert D, Knorr D (2015) The effect of pulsed electric field treatment on immersion freezing, thawing and selected properties of apple tissue. Journal of Food Engineering 146:8-16

157. Flores ES, Mascheroni RH (1988) Determination of heat transfer coefficients for continuous belt freezers. J Food Sci 53(6):18721876

158. Tocci AM, Mascheroni RH (1995) Heat and mass transfer coefficients during the refrigeration, freezing and storage of meats, meat products and analogues. J Food Eng 26(2):147-160

159. Dempsey P, Bansal P (2012) The art of air blast freezing: design and efficiency considerations. Appl Therm Eng 41:71-83

160. Góral D, Kluza F (2006) Physical changes of vegetables during freezing by conventional and impingement methods. Acta Agrophysica 7(1):59-71

161. Góral D, Kluza F (2012) Heat transfer coefficient in impingement fluidization freezing of vegetables and its prediction. International journal of refrigeration 35(4):871-879

162. Khairullah A, Singh RP (1991) Optimization of fixed and fluidized bed freezing processes. Int J Refrig 14(3):176-181

163. Xu Z, Guo Y, Ding S, An K, Wang Z (2014) Freezing by immersion in liquid co 2 at variable pressure: response surface analysis of the application to carrot slices freezing. Innovative Food Science \& Emerging Technologies 22:167-174

164. Salvadori VO, Mascheroni RH (2002) Analysis of impingement freezers performance. J Food Eng 54(2):133-140

165. Agnelli ME, Mascheroni RH (2001) Cryomechanical freezing. a model for the heat transfer process. J Food Eng 47(4):263-270

166. Li J, Chotiko A, Kyereh E, Zhang J, Liu C, Ortega V, Vandeker R, Bankston D, Sathivel S (2017) Development of a combined osmotic dehydration and cryogenic freezing process for minimizing quality changes during freezing with application to fruits and vegetables. Journal of Food Processing and Preservation 41(1):e12926

167. Lucas T, Raoult-Wack AL (1998) Immersion chilling and freezing in aqueous refrigerating media: review and future trends: réfrigération et congélation par immersion dans des milieux réfrigérants: revue et tendances futures. Int $\mathrm{J}$ Refrig 21(6):419-429

168. Galetto CD, Verdini RA, Zorrilla SE, Rubiolo AC (2010) Freezing of strawberries by immersion in $\mathrm{CaCl} 2$ solutions. Food Chem 123(2):243-248

169. Verboven P, Scheerlinck N, Nicolai BM (2003) Surface heat transfer coefficients to stationary spherical particles in an experimental unit for hydrofluidisation freezing of individual foods. International journal of refrigeration 26(3):328-336

170. Wu XF, Zhang M, Adhikari B, Sun J (2017) Recent developments in novel freezing and thawing technologies applied to foods. Critical reviews in food science and nutrition 57(17):3620-3631

171. Kennedy C, Archer GP (1997) Maximizing quality and stability of frozen foods: a producers guide to the state of the art. Report 2 of the EU concerted action project 'the preservation of frozen food quality and safety throughout the distribution chain'(CT961180) pages $1-17$

172. Hirsh AG (1987) Vitrification in plants as a natural form of cryoprotection. Cryobiology 24(3):214-228
173. Kiani H, Zhang Z, Delgado A, Sun DW (2011) Ultrasound assisted nucleation of some liquid and solid model foods during freezing. Food Res Int 44(9):2915-2921

174. LeBail A, Chevalier D, Mussa DM, Ghoul M (2002) High pressure freezing and thawing of foods: a review. Int J Refrig 25(5):504-513

175. Orlowska M, Havet M, Le-Bail A (2009) Controlled ice nucleation under high voltage dc electrostatic field conditions. Food research international 42(7):879-884

176. James C, Reitz B, James SJ (2015) The freezing characteristics of garlic bulbs (Allium sativum L.) frozen conventionally or with the assistance of an oscillating weak magnetic field. Food and bioprocess technology 8(3):702-708

177. Mok JH, Her T, Kang JY, Hoptowit R, Jun S (2017) Effects of pulsed electric field (PEF) and oscillating magnetic field (OMF) combination technology on the extension of supercooling for chicken breasts. J Food Eng 196:27-35

178. Otero L, Rodríguez AC, Pérez-mateos M, Sanz PD (2016) Effects of magnetic fields on freezing: application to biological products. Comprehensive Reviews in Food Science and Food Safety 15(3):646-667

179. Rodríguez AC, Otero L, Cobos JA, Sanz PD (2019) Electromagnetic freezing in a widespread frequency range of alternating magnetic fields. Food Engineering Reviews 11(2):93-103

180. Xin Y, Zhang M, Adhikari B (2014) The effects of ultrasoundassisted freezing on the freezing time and quality of broccoli (Brassica oleracea L. var. botrytis 1.) during immersion freezing. Int J Refrig 41:82-91

181. Cheng XF, Zhang M, Adhikari B, Islam MN, Xu BG (2014) Effect of ultrasound irradiation on some freezing parameters of ultrasound-assisted immersion freezing of strawberries. International Journal of Refrigeration 44:49-55

182. Rambhatla S, Ramot R, Bhugra C, Pikal MJ (2004) Heat and mass transfer scale-up issues during freeze drying: II. control and characterization of the degree of supercooling. Aaps Pharmscitech 5(4):54-62

183. Shimoyamada M, Tômatsu K, Watanabe K (1999) Effect of precooling step on formation of soymilk freeze-gel. Food science and technology research 5(3):284-288

184. Kim J, Chun HH, Park S, Choi D, SR Choi SOh, Yoo SM (2014) System design and performance analysis of a quick freezer using supercooling. J Biosyst Eng 39(4):330-335

185. Kobayashi R, Kimizuka N, Watanabe M, Suzuki T (2015) The effect of supercooling on ice structure in tuna meat observed by using $\mathrm{x}$-ray computed tomography. International Journal of Refrigeration 60:270-277

186. Kobayashi R, Suzuki T (2019) Effect of supercooling accompanying the freezing process on ice crystals and the quality of frozen strawberry tissue. International Journal of Refrigeration 99:94-100

187. Zaritzky NE (2008) Frozen storage. Frozen Food Science and Technology, 224-247

188. Goncalves EM, Abreu M, Brandao TRS, Silva CLM (2011) Degradation kinetics of colour, vitamin c and drip loss in frozen broccoli (Brassica oleracea L. ssp. Italica) during storage at isothermal and non-isothermal conditions. Int $\mathrm{J}$ Refrig 34(8):2136-2144

189. Reid DS, Kerr W, Hsu J (1994) The glass transition in the freezing process. In: Water in foods, pages 483-494. Elsevier

190. van der Sman RGM, Meinders MBJ (2013) Moisture diffusivity in food materials. Food chemistry 138(2-3):1265-1274

191. Griffith M, Ewart KV (1995) Antifreeze proteins and their potential use in frozen foods. Biotechnology advances 13(3):375-402

192. Budke C, Heggemann C, Koch M, Sewald N, Koop T (2009) Ice recrystallization kinetics in the presence of synthetic antifreeze 
glycoprotein analogues using the framework of LSW theory. The Journal of Physical Chemistry B 113(9):2865-2873

193. Martins RC, Almeida MG, Silva CLM (2004) The effect of home storage conditions and packaging materials on the quality of frozen green beans. Int J Refrig 27(8):850-861

194. Eisenberg DP, Steif PS, Rabin Y (2014) On the effects of thermal history on the development and relaxation of thermo-mechanical stress in cryopreservation. Cryogenics 64:86

195. Nesvadba P (2008) Thermal properties and ice crystal development in frozen foods. Frozen food science and technology, pp $1-25$

196. Ferreira A, Canet W, Alvarez MD, Tortosa ME (2006) Freezing, thawing and cooking effects on quality profile assessment of green beans (cv. Win). Eur Food Res Technol 223(4):433

197. Van Buggenhout S, Messagie I, Maes V, Duvetter T, van Loey A, Hendrickx M (2006) Minimizing texture loss of frozen strawberries: effect of infusion with pectinmethylesterase and calcium combined with different freezing conditions and effect of subsequent storage/thawing conditions. Eur Food Res Technol 223(3):395

198. James C, James SJ (2010) Freezing/thawing. Handbook of meat processing, pp 105-124

199. James SJ, James C, Purnell G (2017) Microwave-assisted thawing and tempering. In: The microwave processing of foods (Second Edition), pages 252-272 Elsevier

200. Li B, Sun DW (2002) Novel methods for rapid freezing and thawing of foods-a review. Journal of food engineering 54(3):175-182

201. Cheftel JC, Levy J, Dumay E (2000) Pressure-assisted freezing and thawing: principles and potential applications. Food Reviews International 16(4):453-483

202. Kristiawan M, Chaunier L, Della Valle G, Ndiaye A, Vergnes B (2016) Modeling of starchy melts expansion by extrusion. Trends in food science \& technology 48:13-26

203. Kristiawan M, Kansou K, Della Valle G (2017) Integration of basic knowledge models for the simulation of cereal foods processing and properties. In: Measurement, modeling and automation in advanced food processing, pages 1-27. Springer

204. Van der Sman RGM, Bows JR (2017) Critical factors in microwave expansion of starchy snacks. J Food Eng 211:69-84

205. van der Sman RGM (2018) Clumping of frozen par-fried foods: lessons from frosting on structured surfaces. Food Structure

206. Galindo FG, Elias L, Gekas V, Herppich WB, Smallwood M, Sommarin M, Worrall D, Sjöholm I (2005) On the induction of cold acclimation in carrots (Daucus carota L.) and its influence on storage performance. Food research international 38(1):29-36

207. Leong SY, Du D, Oey I (2018) Pulsed electric fields enhances calcium infusion for improving the hardness of blanched carrots. Innovative food science \& emerging technologies 47:46-55

208. Mizrahi S (1996) Leaching of soluble solids during blanching of vegetables by ohmic heating. J Food Eng 29(2):153-166

209. Parniakov O, Bals O, Lebovka N, Vorobiev E (2016) Effects of pulsed electric fields assisted osmotic dehydration on freezingthawing and texture of apple tissue. Journal of Food Engineering 183:32-38

210. Tylewicz U, Tappi S, Mannozzi C, Romani S, Dellarosa N, Laghi L, Ragni L, Rocculi P, Dalla Rosa M (2017) Effect of pulsed electric field (PEF) pre-treatment coupled with osmotic dehydration on physico-chemical characteristics of organic strawberries. J Food Eng 213:2-9

211. Dermesonlouoglou E, Zachariou I, Andreou V, Taoukis PS (2018) Quality assessment and shelf life modeling of pulsed electric field pretreated osmodehydrofrozen kiwifruit slices. International Journal of Food Studies 7(1):34-51

212. Tijskens LMM, Waldron $\mathrm{KW}, \mathrm{Ng} \mathrm{A}$, Ingham L, Van Dijk C (1997) The kinetics of pectin methyl esterase in potatoes and carrots during blanching. Journal of food engineering 34(4):371385

213. Tijskens LMM, Rodis PS, Hertog MLATM, Waldron KW, Ingham L, Proxenia N, Van Dijk C (1997) Activity of peroxidase during blanching of peaches, carrots and potatoes. Journal of food engineering 34(4):355-370

214. Verlinden BE, Yuksel D, Baheri M, De Baerdemaeker J, van Dijk C (2000) Low temperature blanching effect on the changes in mechanical properties during subsequent cooking of three potato cultivars. International journal of food science \& technology 35(3):331-340

215. Tijskens LMM, Schijvens EPHM, Biekman ESA (2001) Modelling the change in colour of broccoli and green beans during blanching. Innovative Food Science \& Emerging Technologies 2(4):303-313

216. Gonċalves EM, Pinheiro J, Abreu M, Brandão TRS, Silva CLM (2010) Carrot (daucus carota 1.) peroxidase inactivation, phenolic content and physical changes kinetics due to blanching. J Food Eng 97(4):574-581

217. Van der Sman RGM (2003) Simple model for estimating heat and mass transfer in regular-shaped foods. Journal of food engineering 60(4):383-390

218. Van der Sman RGM (2008) Scale analysis and integral approximation applied to heat and mass transfer in packed beds. J Food Eng 85(2):243-251

219. Garrote RL, Silva ER, Bertone RA, Roa RD (2004) Predicting the end point of a blanching process. LWT-Food Science and Technology 37(3):309-315

220. Deng LZ, Pan Z, Mujumdar AS, Zhao JH, Zheng ZA, Gao ZJ, Xiao HW (2019) High-humidity hot air impingement blanching (hhaib) enhances drying quality of apricots by inactivating the enzymes, reducing drying time and altering cellular structure. Food Control 96:104-111

221. Moreno J, Chiralt A, Escriche I, Serra JA (2000) Effect of blanching/osmotic dehydration combined methods on quality and stability of minimally processed strawberries. Food Research International 33(7):609-616

222. Wu Y, Joseph S, Aluru NR (2009) Effect of cross-linking on the diffusion of water, ions, and small molecules in hydrogels. The Journal of Physical Chemistry B 113(11):3512-3520

223. Momot KI (2011) Diffusion tensor of water in model articular cartilage. Eur Biophys J 40(1):81-91

224. Van der Sman RGM (2008) Prediction of enthalpy and thermal conductivity of frozen meat and fish products from composition data. J Food Eng 84(3):400-412

225. Hagiwara T, Sakiyama T, Watanabe H (2009) Estimation of water diffusion coefficients in freeze-concentrated matrices of sugar solutions using molecular dynamics: correlation between estimated diffusion coefficients and measured ice-crystal recrystallization rates. Food biophysics 4(4):340 346

226. Miles CA, van Beek G, Veerkamp CH (1983) Calculation of thermophysical properties of foods. Physical properties of foods/edited by R Jowitt.. others

Publisher's Note Springer Nature remains neutral with regard to jurisdictional claims in published maps and institutional affiliations. 